\title{
ENDOTHELIAL-MELANOMA CELL INTERACTIONS IN THE FORMATION OF BRAIN METASTASES
}

\author{
Ph.D. Thesis \\ Csilla Fazakas \\ Supervisor: István Krizbai M.D., Ph.D., D.Sc. \\ Institute of Biophysics, Biological Research Centre \\ Hungarian Academy of Sciences
}

Szeged

2014 


\section{Table of Contents}

List of publications.............................................................ii

Abbreviations.........................................................................v

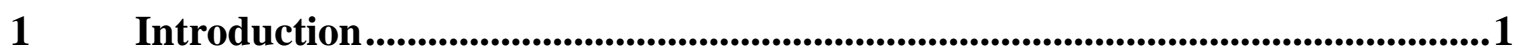

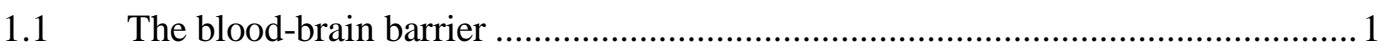

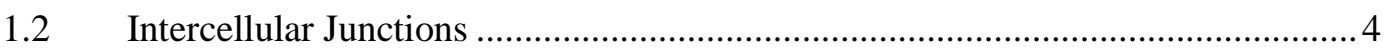

$1.3 \quad$ Interactions of melanoma cells with the blood-brain barrier...................................5

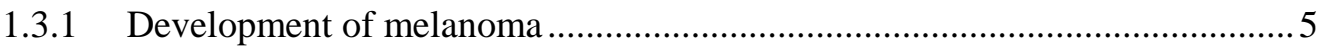

1.3.2 Molecular mechanisms of extravasation of tumor cells................................ 6

1.3.2.1 Surface molecules involved in melanoma extravasation ................................... 7

1.3.2.2 Proteolytic enzymes implicated in the migration of melanoma cells ................... 8

1.3.2.3 Signaling pathways involved in melanoma extravasation ............................... 9

1.3.2.4 Types of cancer cell movement …............................................................ 9

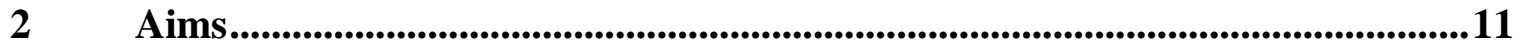

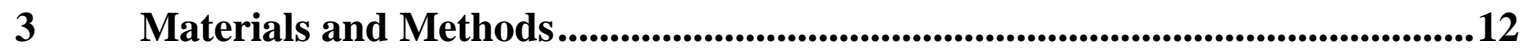

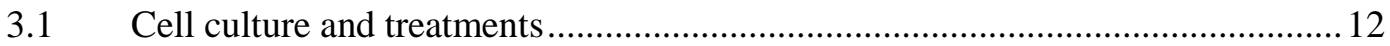

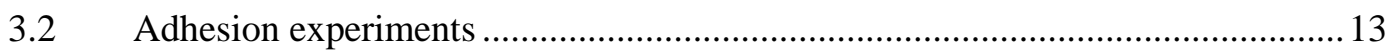

3.3 Measurement of adhesion forces between melanoma and endothelial cells using atomic force microscopy (AFM) ........................................................ 13

3.4 Immunofluorescence and phalloidin staining of the actin-cytoskeleton ............... 15

3.5 Measurement of transendothelial electrical resistance (TEER) …........................ 16

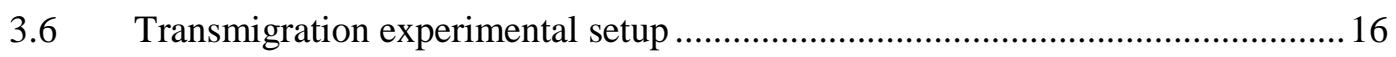

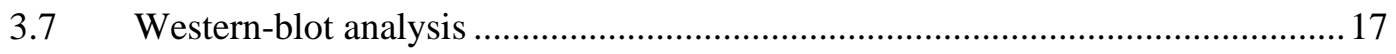

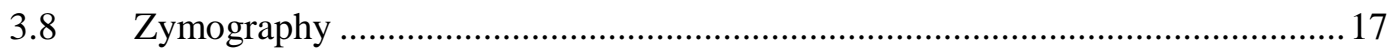




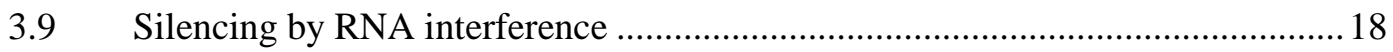

3.10 Evaluation of brain metastasis formation in vivo .............................................. 19

4 Results

4.1 Interaction of melanoma cells with the in vitro BBB model: adhesion and transmigration. .20

4.2 Effects of melanoma transmigration on BBB integrity .22

4.2.1 Melanoma cells impair the integrity of endothelial barrier.

4.2.2 Paracellular transmigration of melanoma cells induces disassembly of endothelial tight junctions.

4.2.3 Interaction between melanoma and cerebral endothelial cells induces EC apoptosis

4.3 Role of proteolysis in melanoma transmigration. .26

4.4 Role of the Rho/ROCK signaling pathway in the transmigration of melanoma cells

4.4.1 Rho/ROCK inhibition fosters the mesenchymal phenotype of metastatic melanoma

4.4.2 Mesenchymal phenotype of melanoma cells enhances their adhesion to the cerebral endothelium.

4.4.3 Rho-kinase inhibition increases the adhesion forces between melanoma cells and endothelial cells

4.4.4 ROCK inhibition raises the transmigration rate of melanoma cells through CECs

4.4.5 Melanoma RhoA inhibition is responsible for the increased transmigration rate

4.4.6 ROCK inhibitor promotes melanoma brain metastasis formation in vivo..... 35 
5.2 Melanoma cells impair the integrity of the BBB and use the paracellular pathway of transmigration

5.3 Role of proteases in the extravasation of melanoma cells .....................................38

5.4 Role of the ROCK inhibition-induced mesenchymal phenotype in the interaction of melanoma cells with the brain endothelium.....................................4 40

$6 \quad$ Summary ..................................................................................................................44

$7 \quad$ References ........................................................................................................................4

Acknowledgements .........................................................................................................................54

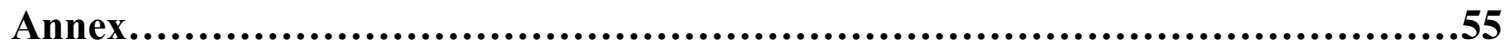




\section{List of Publications}

Full papers directly related to the subject of the thesis

I. Fazakas, C. *, Wilhelm, I. *, Nagyoszi, P., Farkas, A.E., Hasko, J., Molnar, J., Bauer, H., Bauer, H.C., Ayaydin, F., Dung, N.T., Siklos, L., and Krizbai, I.A. (2011). Transmigration of melanoma cells through the blood-brain barrier: role of endothelial tight junctions and melanoma-released serine proteases. PLoS One 6, e20758. $(*=c o-f i r s t$ authors) (IF2011: 4.092)

II. Wilhelm, I.*, Fazakas, C.*, Molnar, J., Hasko, J., Vegh, A.G., Cervenak, L., Nagyoszi, P., Nyul-Toth, A., Farkas, A.E., Bauer, H., Guillemin, G.J., Bauer, H.C., Varo, G., and Krizbai, I.A. (2014). Role of Rho/ROCK signaling in the interaction of melanoma cells with the blood-brain barrier. Pigment Cell. Melanoma Res. 27, 113-123. ( ${ }^{*}=\mathrm{co}-$-first authors) (IF2012: 5.839)

III. Wilhelm, I., Fazakas, C., and Krizbai, I.A. (2011). In vitro models of the blood-brain barrier. Acta Neurobiol. Exp. (Wars) 71, 113-128. (IF2011: 2.110)

\section{Full papers not included in the thesis}

1. Wilhelm, I., Molnar, J., Fazakas, C., Hasko, J., and Krizbai, I.A. (2013). Role of the blood-brain barrier in the formation of brain metastases. Int. J. Mol. Sci. 14, 13831411. (IF2012: 2.464)

2. Balint, Z., Zabini, D., Konya, V., Nagaraj, C., Vegh, A.G., Varo, G., Wilhelm, I., Fazakas, C., Krizbai, I.A., Heinemann, A., Olschewski, H., and Olschewski, A. (2013). Double-stranded RNA attenuates the barrier function of human pulmonary artery endothelial cells. PLoS One 8, e63776. (IF2012: 3.730)

3. Sziraki, I., Erdo, F., Trampus, P., Sike, M., Molnar, P.M., Rajnai, Z., Molnar, J., Wilhelm, I., Fazakas, C., Kis, E., Krizbai, I., and Krajcsi, P. (2013). The use of microdialysis techniques in mice to study P-gp function at the blood-brain barrier. J. Biomol. Screen. 18, 430-440. (IF2012: 2.207)

4. Vegh, A.G., Fazakas, C., Nagy, K., Wilhelm, I., Molnar, J., Krizbai, I.A., Szegletes, Z., and Varo, G. (2012). Adhesion and stress relaxation forces between melanoma and cerebral endothelial cells. Eur. Biophys. J. 41, 139-145. (IF2012: 2.274) 
5. Mallareddy, J.R., Toth, G., Fazakas, C., Molnar, J., Nagyoszi, P., Lipkowski, A.W., Krizbai, I.A., and Wilhelm, I. (2012). Transport characteristics of endomorphin-2 analogues in brain capillary endothelial cells. Chem. Biol. Drug Des. 79, 507-513. (IF2012: 2.469)

6. Hornok, V., Bujdoso, T., Toldi, J., Nagy, K., Demeter, I., Fazakas, C., Krizbai, I., Vecsei, L., and Dekany, I. (2012). Preparation and properties of nanoscale containers for biomedical application in drug delivery: preliminary studies with kynurenic acid. $\mathbf{J}$. Neural Transm. 119, 115-121. (IF2012: 2.730)

7. Vegh, A.G., Fazakas, C., Nagy, K., Wilhelm, I., Krizbai, I.A., Nagyoszi, P., Szegletes, Z., and Varo, G. (2011). Spatial and temporal dependence of the cerebral endothelial cells elasticity. J. Mol. Recognit. 24, 422-428. (IF2011: 3.310)

8. Sziraki, I., Erdo, F., Beery, E., Molnar, P.M., Fazakas, C., Wilhelm, I., Makai, I., Kis, E., Heredi-Szabo, K., Abonyi, T., Krizbai, I., Toth, G.K., and Krajcsi, P. (2011). Quinidine as an $\mathrm{ABCB} 1$ probe for testing drug interactions at the blood-brain barrier: an in vitro in vivo correlation study. J. Biomol. Screen. 16, 886-894. (IF2011: 2.049)

9. Nagyoszi, P., Wilhelm, I., Farkas, A.E., Fazakas, C., Dung, N.T., Hasko, J., and Krizbai, I.A. (2010). Expression and regulation of toll-like receptors in cerebral endothelial cells. Neurochem. Int. 57, 556-564. (IF2010: 3.601)

10. Wilhelm, I., Nagyoszi, P., Farkas, A.E., Couraud, P.O., Romero, I.A., Weksler, B., Fazakas, C., Dung, N.T., Bottka, S., Bauer, H., Bauer, H.C., and Krizbai, I.A. (2008). Hyperosmotic stress induces Axl activation and cleavage in cerebral endothelial cells. J. Neurochem. 107, 116-126. (IF2008: 4.500) 


\section{Abbreviations}

\begin{tabular}{|c|c|}
\hline $\mathrm{ABC}$ & - ATP Binding Cassette \\
\hline AFM & - Atomic Force Microscopy \\
\hline AJ & - Adherens Junction \\
\hline BBB & - Blood-Brain Barrier \\
\hline BSA & - Bovine Serum Albumin \\
\hline CEC & - Cerebral Endothelial Cell \\
\hline CDKN2A & - Cyclin dependent kinase inhibitor of kinase $2 \mathrm{~A}$ \\
\hline CNS & - Central Nervous System \\
\hline ConA & - Concanavalin A \\
\hline DPPIV & - Dipeptidyl dipeptidase IV \\
\hline EBM & - Endothelial Basal Medium \\
\hline $\mathrm{EC}$ & - Endothelial Cell \\
\hline ECM & - Extracellular Matrix \\
\hline EDTA & - Ethylenediaminetetraacetic Acid \\
\hline EGM & - Endothelial Growth Medium \\
\hline ERK & - Extracellular signal-Regulated Kinase \\
\hline FAP & - Fibroblast Activation Protein \\
\hline FBS & - Fetal Bovine Serum \\
\hline GDNF & - Glial cell-Derived Neurotrophic Factor \\
\hline hCMEC/D3 & - human Cerebral Microvascular Endothelial Cells / D3 \\
\hline ICAM & - Intercellular Adhesion Molecule \\
\hline JAM & - Junctional Adhesion Molecule \\
\hline MAPK & - Mitogen Activated Protein Kinase \\
\hline MCAM & - Melanoma Cell Adhesion Molecule \\
\hline MC1R & - Melanocortin-1 receptor \\
\hline MMP & - Matrix Metalloprotease \\
\hline OG & - Oregon Green \\
\hline PBS & - Phosphate-Buffered Saline \\
\hline PDZ & - Psd95/discs large 1/Zonula Occludens-1 \\
\hline PECAM-1 & - Platelet Endothelial Cell Adhesion Molecule-1 \\
\hline PI3K & - Phosphoinositide 3-kinase \\
\hline PTEN & - Phosphatase and Tensin homologue \\
\hline RBEC & - Rat Brain Endothelial Cell \\
\hline ROCK & - Rho associated protein kinase \\
\hline RPMI & - Roswell Park Memorial Institute \\
\hline TGF-beta & - Transforming Growth Factor beta \\
\hline TJ & - Tight Junction \\
\hline U-PA & - Urokinase Plasminogen Activator \\
\hline U-PAR & - Urokinase Plasminogen Activator Surface Receptor \\
\hline VCAM & - Vascular Cell Adhesion Molecule \\
\hline $\mathrm{ZO}$ & - Zonula Occludens \\
\hline
\end{tabular}




\section{Introduction}

Brain metastases are frequent complications for cancer patients (10\%-30\%) and result in high mortality rate. The overall life expectancy is limited to a few months (4-5 months) even after intensive multimodal therapy (Fokas, Steinbach \& Rodel 2013).

Estimations of occurrence show that in the United States brain metastases are 10 times more common than primary malignant brain tumors (Davis et al. 2012, Platta et al. 2010). Metastatic cells of different origin display considerable differences in the tendency to access the central nervous system (CNS), with lung cancer (40\%-50\%), followed by breast cancer (15\%-25\%) and malignant melanoma (5\%-20\%) resulting most frequently in brain metastasis (Wen, Black \& Loeffler 2011, Barnholtz-Sloan et al. 2004). Among these tumors, melanoma is most prone to form brain metastases: diagnosed in 40\%-50\% of the cases, which after autopsy, increase with an additional 30\%-40\%. Emergence of metastases involves multistep processes: from tumor cells invading the local tissue and entering the blood or lymphatic vessels, to extravasation and colonization of the target organs. Since the central nervous system lacks a lymphatic drainage, metastatic tumor cells can reach the brain only via the blood vessels. However, between the blood and the CNS there are barrier interfaces, including the blood-cerebrospinal fluid (CSF) barrier, the arachnoid epithelium between blood and subarachnoid CSF and the blood-brain barrier (BBB). To colonize the brain parenchyma tumor cells have to pass mainly the blood-brain barrier.

\subsection{The blood-brain barrier}

The blood-brain barrier is an active interface between the circulation and the central nervous system, and has an important role in maintaining the homeostasis of the CNS. This is achieved by the control of the ion balance, nutrient supply as well as through elimination of metabolic compounds. Hence, the BBB has dual task, operates both as a barrier and as a carrier too.

As a barrier, it restricts the transport of potentially toxic or harmful substances from the blood to the brain, which is secured through a fourfold defense line: 
i. The interendothelial tight junctions form the paracellular barrier and are responsible for regulation of ion and solute movement between adjoining cells.

ii. Brain endothelial cells show low level of endocytosis and transcytosis thus conferring a transcellular barrier.

iii. The enzymatic barrier results from a complex set of enzymes including acetyl-cholinesterase, alkaline phosphatase, gamma-glutamyl transpeptidase, monoamine oxidases, and other drug metabolizing enzymes capable to degrade different chemical compounds.

iv. Nevertheless, the presence of efflux transporters (ATP-binding cassette $(\mathrm{ABC})$ transporters) at the cerebral endothelium also has a critical role in $\mathrm{BBB}$ barrier function. The foremost $\mathrm{ABC}$ transporters are $\mathrm{P}$-glycoprotein (P-gp, ABCB1), the multidrug resistance-associated proteins (MRPs: $\mathrm{ABCC} 1$ and $\mathrm{ABCC} 4)$ and breast cancer resistance protein (BCRP, ABCG2).

Beyond the barrier function, the BBB ensures the transport of nutrients to the brain and removal of metabolites. Blood oxygen and carbon dioxide, as well as small lipid soluble molecules diffuse passively across the endothelium. Cerebral endothelial cells (CECs) express a vast number of specific solute carriers (SLC) which transport essential nutrients like glucose and amino acids (Abbott et al. 2010). Some substances are transported through receptor mediated transcytosis (peptides and proteins) or by adsorptive transcytosis (positively charged molecules).

The BBB functions as listed above are mainly provided by the endothelial cells (ECs) of brain capillaries. Formation and maintenance of the special barrier characteristics of cerebral endothelial cells are supported by pericytes and astrocytes (Figure 1). Additionally, the BBB together with neurons and microglial cells is part of the neurovascular unit (Abbott, Ronnback \& Hansson 2006).

Endothelial cells are ensheathed by a basal membrane, which consists mainly of collagen IV, fibronectin, laminin and proteoglycans. The extracellular matrix (ECM) participates in endothelial barrier responses by way of binding to endothelial cell surface integrins at focal adhesions. Disruption of the basal membrane might lead to alterations affecting the junctional proteins and the integrity of the barrier. In several pathological 
conditions, impaired $\mathrm{BBB}$ properties have been associated to disruption of the extracellular matrix (Hawkins, Davis 2005). Furthermore, the basal membrane is involved in survival of tumor cells during brain colonization (Carbonell et al. 2009).

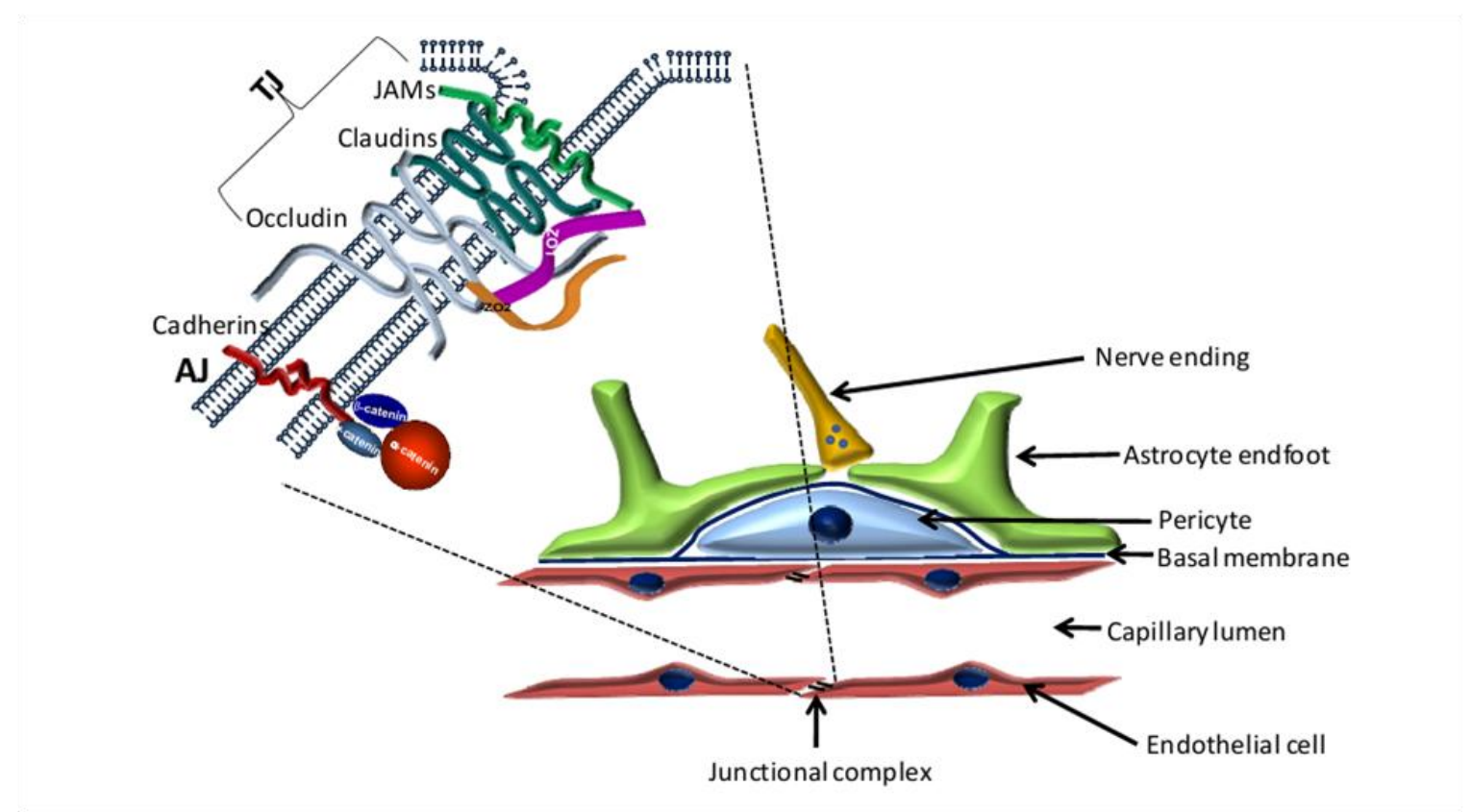

Figure 1: Schematic diagram of the blood-brain barrier. The core anatomical structure of the BBB is formed by cerebral endothelial cells, which share common basal membrane with pericytes, and are covered by astrocytic endfeet. Endothelial cells are interconnected by a continuous line of tight junctions. The inset illustrates the molecular structure of the junctional complex. TJ = tight junction; $\mathbf{A J}=$ adherens junction.

Pericytes are located in the duplication of the basal membrane and play an important role in the regulation of endothelial proliferation, angiogenesis and inflammatory processes (Dore-Duffy 2008). Nevertheless, pericytes are required to support BBB integrity (Armulik et al. 2010).

Astrocytic endfeet encircle the cerebral vessels, covering a significant part of the endothelial surface (Kacem et al. 1998). Astrocytes or astrocyte-conditioned media improve endothelial barrier functions. Astrocytes release important regulatory factors including TGF-beta, glial cell derived neurotrophic factor (GDNF) (Igarashi et al. 1999), interleukin-6 and basic fibroblast growth factor (Sobue et al. 1999).

Neurons might also regulate important aspects of the BBB function and can induce the expression of BBB-related enzymes in cultured endothelial cells (Tontsch, 
Bauer 1991); nevertheless, neuronal mediators affect cerebral blood flow and vessel dynamics.

\subsection{Intercellular Junctions}

Interendothelial junctions including tight junctions (TJs) and adherens junctions (AJs) (Figure 1, inset) seal the paracellular space between endothelial cells. Tight junctions can be visualized as belt-like structures at the apical region of the cells, forming a physical barrier that regulates paracellular movement of ions and solutes ("gate function"). Restriction of ion movement results in high transendothelial electrical resistance (TEER). Through separation of the apical and the basolateral membrane domains TJs contribute to the polarization of the cell ("fence function") (GonzalezMariscal et al. 2003).

Tight junctions are formed by transmembrane proteins that seal the paracellular gap and peripheral proteins, which are located at the cytoplasmic surface of junctions and interact with the transmembrane components. Three families of integral membrane proteins represent the key components of TJs. First, the tetraspan proteins are represented by the Marvel (occludin (Furuse et al. 1993), tricellulin/MarvelD2, MarvelD3) and claudin families. Brain endothelial cells express only a few from the claudin family, mainly claudin-5 and to a smaller extent claudin $-3,-10,-12$, yet claudin-10 and -22 may also contribute to TJ formation at the BBB (Ohtsuki et al. 2008). The maintenance of low paracellular permeability is mainly controlled by claudin-5. Second, members of single span proteins of the immunoglobulin superfamily localize to ECs junctions, like endothelial specific adhesion molecule and junctional adhesion molecules (JAM-A, -B, -C) (Martin-Padura et al. 1998). Third, non-immunglobulin type single span proteins are represented by crumbs homolog 3 (CRB3) and Bves/Pop1 (Blood vessel epicardial substance), which are relevant mainly for epithelial cells (Bauer et al. 2011).

Cytoplasmic scaffold proteins contain PDZ (Psd95/discs large/ZO-1) domains, which link transmembrane proteins to the actin cytoskeleton. These include zonula occludens (ZO)-1 (Stevenson et al. 1986) and ZO-2 (Gumbiner, Lowenkopf \& Apatira 1991). Besides PDZ domain proteins, the junctional plaque include cingulin (Citi et al. 
1989) and JACOP (junction-associated coiled-coil protein)/paracingulin (Ohnishi et al. 2004) .

Scaffolding proteins (e.g. ZO proteins) recruit several signaling proteins to tight junctions. Protein kinases (A, B, C), mitogen activated protein kinases (MAPK) have been involved in the regulation of BBB properties. The small GTPase Rho and Rac proteins also regulate TJ assembly and disassembly of ECs. Activation of RhoA and its effector ROCK leads to permeability increase, whereas Rac activation is barrier protective (Terry et al. 2010, Gonzalez-Mariscal, Tapia \& Chamorro 2008).

Development and maintenance of tight junctions is supported by adherens junctions, which are located basolaterally to TJs and also form a continuous line along cell-cell boundaries. Adherens junctions (AJs) are ubiquitous and essential in the development of the vasculature, in initiation and maintenance of cell-cell junctions. Transmembrane proteins of adherens junctions are members of the cadherin family. Endothelial cells express mainly vascular endothelial (VE-) cadherin, an important determinant of vascular integrity, connected through the catenins (alpha, beta, and p120) to the cytoskeleton. The main role of catenins is to anchor the cadherin complex to the actin cytoskeleton, yet they also participate in cell and developmental signaling pathways (Stamatovic, Keep \& Andjelkovic 2008). Additionally, the nectin-afadin system plays important role both in organization and in formation of AJs and TJs. Nectin is linked to afadin (AF6), and through afadin to actin, but might interact with TJ proteins (ZO-1, JAMs) too (Takahashi et al. 1999, Fukuhara et al. 2002).

Integrity of the BBB has been reported to be compromised in several neurological disorders including cerebral ischemia, inflammation and brain tumors. Moreover, the $\mathrm{BBB}$ is actively involved in the transmigration of leukocytes and tumor cells during inflammation and metastasis formation.

\subsection{Interactions of melanoma cells with the blood-brain barrier}

\subsubsection{Development of melanoma}

Melanoma is a malignant tumor that arises from melanocytes, the pigmented cells of the skin. Development of melanoma has several sequential steps starting from structurally normal melanocytes. Early melanoma shows a radial growth in the epidermis. 
With the progression of melanoma, tumor cells extend into the dermis (vertical growth phase). At this stage, melanoma cells are able to enter blood or lymphatic vessels and develop metastases in distant organs (Meier et al. 1998). Conversion of melanocytes to melanoma involves several genetic and molecular changes. Genetic susceptibility (loss of CDKN2A locus, MC1R) and intermittent sun exposure are well known contributors to melanoma risk. On the other hand, somatic mutations that overactivate the Ras/MAPK pathway (NRAS and BRAF) or Ras/PI3K signaling (PTEN deleted or AKT activated) facilitate tumor cell growth, survival and invasion (Whiteman, Pavan \& Bastian 2011, Hocker, Singh \& Tsao 2008).

Despite of being relatively rare compared with other skin cancers melanoma accounts for a large majority of skin cancer associated deaths. This is partially due to the high incidence of brain metastasis. Melanoma brain metastases may have intraparenchymal (49\%), leptomeningeal (22\%) and dural (32\%) manifestations (Fidler et al. 1999). Migration of tumor cells through the BBB is a prerequisite of parenchymal brain metastasis formation.

Interestingly, metastatic tumor cells are able to respond to different organ-specific stimuli, i.e. growth factors present in or produced by the target organ. A possible reason for the high incidence of melanoma brain metastases might be a homing behavior. Based on the "seed and soil" hypothesis metastatic tumor cells (seed) show a distinct preference for a given organ that is more susceptible (soil) and sustains tumor growth (Fidler 2011). Melanocytes originate from pluripotent neural crest cells, sharing an embryologic origin with neurons. Neurotrophins (present both in the skin and in the CNS) as well as neurotrophin-regulated heparanase have been ascribed to play a significant role in melanoma brain invasion (Denkins et al. 2004).

\subsubsection{Molecular mechanisms of extravasation of tumor cells}

In order to colonize the target organs tumor cells need to exit the vasculature (extravasation). Extravasation involves the arrest of tumor cells in the vasculature, passage through or between endothelial cells, termed transendothelial migration and the penetration through the subendothelial basal membrane. Studies of leukocyte extravasation revealed the main molecular aspects of leukocyte transendothelial migration that may be applied to understand cancer cell extravasation. The steps of transmigration 
in the case of immune cells are rolling, adhesion and diapedesis/transmigration. The sequential steps - attachment (weak and stable adhesion), transmigration - of the extravasation process may show similarities between leukocytes and tumor cells. However, due to different physiological, molecular and mechanical characteristics of immune and metastatic cells, there may be significant differences. Conversely, to extravasating leukocytes, migrating tumor cells induce an irreversible impairment of the endothelium (Strell, Entschladen 2008, Wolburg, Wolburg-Buchholz \& Engelhardt 2005).

The process of transendothelial migration of tumor cells is largely uncharacterized, and much of our knowledge comes from studies on endothelial cells of non-cerebral origin, which do not present the special BBB phenotype. Different cell surface and adhesion molecules, proteolytic enzymes and signaling pathways have been shown to facilitate invasive and migratory capacities of melanoma cells and their transfer through endothelial barriers.

However, very few experimental data are available about the interaction of melanoma cells with brain endothelial cells. Key steps in formation of melanoma brain metastasis were determined by in vivo real-time imaging and proved to be the following: arrest at vascular branch points, extravasation, persistent close contacts to microvessels and perivascular growth by vessel cooption (Kienast et al. 2010).

\subsubsection{Surface molecules involved in melanoma extravasation}

The first step in melanoma extravasation is the attachment to the ECs. Several adhesion and junctional molecules are involved in this process. Expression of cognate ligands and receptors is required for tumor cell adhesion to endothelial cells.

In initial adherence of tumor cells selectin-dependent mechanisms may have important role. Melanoma cells express sialyl Lewis $\mathrm{x}$, which is a ligand for endothelial selectin (E-selectin) and might facilitate the attachment to ECs. It has been reported that melanoma brain metastasis formation was ablated by heparin, a potent inhibitor of selectin dependent interactions (Maraveyas et al. 2010).

Neuronal cadherin (N-cadherin) is expressed by ECs as well as by melanoma cells and promotes the adhesion and transendothelial migration subsequently (Qi et al. 2006). 
Integrins are well known to be involved in different cancer metastasis formation. In case of melanoma, the $\alpha v \beta 3$ and $\alpha 4 \beta 1$ integrins were shown to facilitate the transendothelial migration (Voura et al. 2001) .

Several members of the immunoglobulin superfamily of cell adhesion molecules are also key participants of tumor cells' extravasation. For example intercellular adhesion molecule-1 (ICAM-1) (Ghislin et al. 2012), vascular cell adhesion molecule (VCAM-1) (Klemke et al. 2007) and JAMs (Ghislin et al. 2011) may contribute to the interaction of melanoma cells with the endothelium. MCAM/MUC18 (CD146) expression is elevated in melanoma cells compared to melanocytes, and mediates adhesion between melanoma and endothelial cells.

In addition, expression of melanotransferrin on melanoma cells was found to correlate with increased transmigration of melanoma cells through the BBB (Rolland et al. 2009).

\subsubsection{Proteolytic enzymes implicated in the migration of melanoma cells}

Attachment of melanoma cells to endothelial cells is followed by the infiltration through the endothelium, which is facilitated by the produced and released proteases. Tumor-cell secreted proteolytic enzymes are implicated in different steps of cancer invasion and metastasis formation. Several enzymes promote the invasion of host tissue including matrix metalloproteases (MMPs), serine proteases and heparanase. Spreading and metastatic potential often correlates with the secreted and released MMPs and serine proteases, which are responsible for extracellular matrix (ECM) degradation.

It has been shown that MMP-2 is responsible for brain metastasis formation of breast cancer (Mendes, Kim \& Stoica 2005) and melanoma cells (Xie et al. 2006). MMPs might have a putative role in transendothelial migration of tumor cells through the BBB since proteins of the junctional complex are possible targets of these enzymes. MMP-2 and MMP-9 mediate infiltration of leukemic cells through the BBB by disrupting TJ proteins (claudin-5, occludin and ZO-1 as well) (Feng et al. 2011).

Melanoma cells express several serine proteases (plasmin, u-PA, seprase) which play a pivotal role in migration. Plasmin mediates melanoma crossing through the BBB and promotes development of brain metastasis (Perides et al. 2006). Seprase, also known as FAP (fibroblast activation protein), was identified as being expressed by malignant melanoma cells, mostly localized at the invadopodia of migrating cells (Monsky et al. 
1994). Nevertheless, it was established that the u-PAR and seprase colocalize at the invadopodia of malignant melanoma cells (Artym et al. 2002). Interestingly, seprase plays an important role in early dissemination of melanoma from the skin (Waster et al. 2011). However, little is known about its role in melanoma cell transmigration through the brain endothelium.

\subsubsection{Signaling pathways involved in melanoma extravasation}

Several signaling pathways have been shown to play important role in the transendothelial migration of melanoma cells. Src kinase participates in melanoma transendothelial migration (Qi et al. 2005) as well as enhances Rho/ROCK independent movement of melanoma cells (Ahn, Sanz-Moreno \& Marshall 2012). Melanoma cells capable of brain metastasis formation show an enhanced activity of the Yes tyrosine kinase as well (Marchetti et al. 1998) .

The PI3K-AKT pathway regulates cell survival and proliferation; nevertheless, it is overactivated in metastatic melanoma cells. PI3K inhibition could reduce the transendothelial migration of melanoma cells through human umbilical vein endothelial cells (Peng et al. 2005).

Activation of p38 MAPK and ERK1/2 promotes melanoma cell invasion (Colone et al. 2008). In addition, ERK1/2 was shown to be activated in brain endothelial cells being exposed to melanoma cell-conditioned media (Anfuso et al. 2009).

In the metastatic dissemination tumor cell spreading is mediated through constant cytoskeletal remodeling. Rho-kinases (ROCK1 and ROCK2) are the main effectors of the small GTPase RhoA and RhoC, having several substrates (including the LIM-kinases and myosin light chain) involved in the regulation of the cytoskeleton.

\subsubsection{Types of cancer cell movement}

It has been shown that tumor cells are able to adopt two interconvertible types of movement, characterized by mesenchymal and amoeboid (rounded) phenotype (Figure 2). The mesenchymal type exhibits elongated cell morphology, large cellular protrusions and requires high Rac1 activity, reduced Rho/ROCK signaling and exracellular proteolysis. Conversely, amoeboid movement is dependent on elevated Rho/ROCK signaling that ensures for actomyosin contractility (Sahai, Marshall 2003). The possibility to switch 
between these phenotypes allows tumor cells to successfully invade the different types of extracellular matrices (ECMs) (Sanz-Moreno et al. 2008).

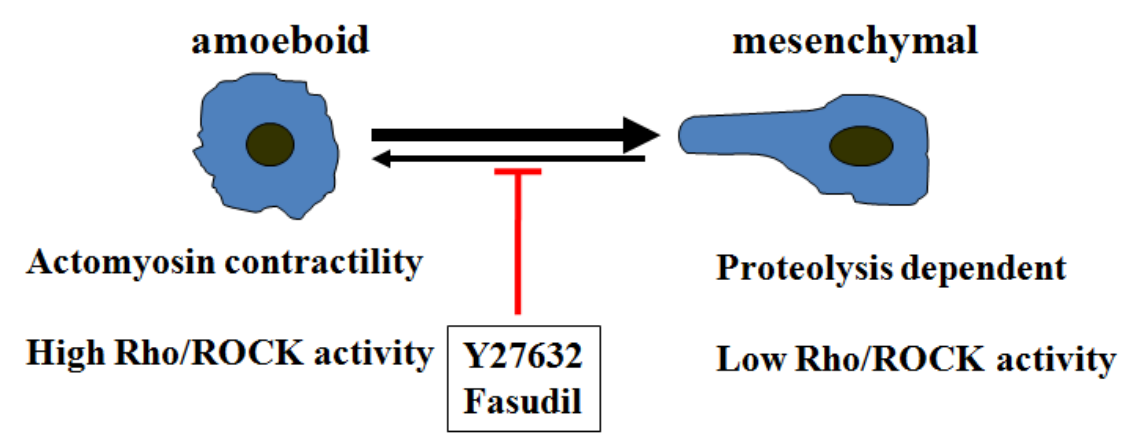

Figure 2: Schematic representation of the two types of movement acquired by cancer cells. Tumor cells are able to switch between a Rac dependent mesenchymal phenotype and a Rho/ROCK dependent amoeboid one to enhance their migration.

It is not surprising therefore, that studies regarding the effects of ROCK inhibition on tumor cell motility, invasion and metastasis formation are contradictory and appear to depend on the tumor cell type. Inhibition of ROCKs has been shown to decrease the invasion and migration of lung (Yang et al. 2012, Xu et al. 2012, Yang et al. 2010), breast (Wyckoff et al. 2006) and hepatocellular carcinoma cells (Itoh et al. 1999). In contrast, in case of osteosarcoma (Yui et al. 2010), pancreatic carcinoma (Fujita et al. 2011), colon carcinoma (Vishnubhotla et al. 2012) and scirrhous gastric carcinoma (Matsuoka et al. 2011) ROCK inhibitors promoted invasive and migratory properties of the cells. Regarding melanoma, inhibition of the Rho/ROCK signaling pathway was shown to alter the expression of tumor progression genes (Spencer et al. 2011), reduce proliferation (Routhier et al. 2010), tumor cell invasion and formation of lung metastases (Kidera et al. 2010).

Additionally, movement of tumor cells might also depend on the physicochemical and biological properties of the extracellular matrix or endothelial barrier they need to cross. Moreover, the Rho/ROCK pathway in both tumor and endothelial cells is likely to play a role in the transendothelial migration. Therefore, ROCK inhibitors might influence (additively or oppositely) this process from the side of both cell types. 


\section{Aims}

Despite therapeutic efforts, brain metastasis has remained one of the most feared complications among cancer patients. The incidence of CNS metastases is very common in patients with melanoma. In order to reach the brain tumor cells must breach the blood-brain barrier, which represents a formidable challenge for metastatic cancer cells. Currently there is still a lack of information on the molecular mechanisms of the formation of brain metastases. Most of our knowledge is based on tumor cell interaction with endothelium of non-cerebral origin. Therefore, in our studies we sought to describe molecular mechanisms involved in the interaction of melanoma cells with the brain endothelium. Our investigations addressed the following specific questions:

1. Do melanoma cells affect the integrity of the BBB during transmigration?

2. What is the route of transmigration of melanoma cells through the BBB?

3. Which are the main proteases facilitating melanoma transendothelial migration?

4. What is the role of Rho/ROCK signaling in melanoma brain metastasis formation? 


\section{Materials and Methods}

\subsection{Cell culture and treatments}

Interaction of melanoma cells with the brain endothelium was studied using the following cell lines: the human microvascular cerebral endothelial cell line hCMEC/D3, the A2058 human melanoma cell line and the murine B16/F10 melanoma cell line. The hCMEC/D3 (Weksler et al. 2005) human cerebral endothelial cells (shortly D3) were grown on rat tail collagen-coated dishes in EBM-2 medium (Lonza) supplemented with EGM-2 Bullet Kit (Lonza) and 5\% FBS (Sigma). A2058 human melanoma cells (obtained from the European Collection of Cell Cultures) were maintained in MEM (Sigma) supplemented with 5\% FBS (Lonza) and Glutamax (Invitrogen). The B16/F10 melanoma cell line was used to confirm the data obtained with human cells and in the in vivo experiments. B16/F10 murine melanoma cells were kept in RPMI medium (Sigma) supplemented with 5\% FBS (Lonza) and Glutamax.

For transmigration experiments primary rat brain endothelial cells (RBECs) were used because of their superior barrier characteristics. Primary rat brain endothelial cells (RBECs) were isolated from 2-week old rats. Briefly, after removal of meninges cerebral cortices were cut into small pieces and digested with $1 \mathrm{mg} / \mathrm{ml}$ collagenase type 2 (Sigma). After separation of myelin by centrifugation in $20 \%$ bovine serum albumin (BSA), a second digestion was performed with $1 \mathrm{mg} / \mathrm{ml}$ collagenase/dispase (Roche). Microvessel fragments were collected after $10 \mathrm{~min} 1000 \bullet \mathrm{g}$ centrifugation on Percoll (Sigma) gradient, and plated onto fibronectin/collagen-coated dishes. Endothelial cells growing out of the microvessels were cultured in DMEM/F12 (Invitrogen), 10\% plasma-derived serum (First Link) and growth factors. In the first two days, $4 \mu \mathrm{g} / \mathrm{ml}$ puromycin was added to remove contaminating cells.

The serine protease inhibitor Pefabloc was used in a concentration of $200 \mu \mathrm{M}$ in transmigration experiments. Y27632 (Tocris) and fasudil (Santa Cruz) (ROCK-I and ROCK-II inhibitors) were used in a concentration of $10 \mu \mathrm{M}$. Selective inhibition of Rho in either RBEC or melanoma cells was performed using CT04 (cell permeable C3 
transferase exoenzyme from Clostridium botulinum inactivating the GTPases RhoA, RhoB, and RhoC, Cytoskeleton Inc.) in a concentration of $1 \mu \mathrm{g} / \mathrm{ml}$ for $150 \mathrm{~min}$.

\subsection{Adhesion experiments}

Brain endothelial cells (RBEC or D3) were grown until confluence in 24-well plates. Melanoma cells (A2058 or B16/F10) were fluorescently labeled using Oregon Green ${ }^{\circledR} 488$ carboxylic acid diacetate succinimidyl ester (shortly: OG, Life technologies) using the protocol supplied by the manufacturer. $5 \cdot 10^{4}$ melanoma cells/well were loaded onto the endothelial cells in serum-free medium and left for different time intervals. Nonattached cells were washed and remaining cells were fixed using ethanol/acetic acid $(95 / 5)$ at $-20^{\circ} \mathrm{C}$ for $5 \mathrm{~min}$. Melanoma cells adhered to endothelial cells were photographed and counted using the Image-Pro Plus software.

\subsection{Measurement of adhesion forces between melanoma and endothelial cells using atomic force microscopy (AFM)}

Instrumentation: Experiments were performed with an Asylum MFP-3D type atomic force microscope (Asylum Research), having an Axiovert 200 microscope as a support, and the MFP-3D Xop driver program, written in Igor Pro software (v. 6.22A, Wavemetrics). Silicon nitride tipless cantilevers were used (MikroMasch). Their spring constant was defined by thermal calibration method (Hutter, Bechhoefer 1993), giving an average of $30 \mathrm{pN} / \mathrm{nm}$. Cantilevers were functionalized with a multilayer build-up, covered with biotinylated-BSA, streptavidin and with biotinylated Concanavalin-A (Vegh et al. 2012, Zhang, Wojcikiewicz \& Moy 2006).

Experimental setup: $10^{3}$ OG-labeled A2058 cells were placed into a $10 \mathrm{~cm}^{2}$ culture dish containing an approximately $2 \mathrm{~cm}^{2}$ area of confluent D3 culture in the middle of the dish. Force measurements (see below) were performed in Leibovitz L-15 medium (Sigma). After 25 min, the medium was replaced with fresh Leibovitz L-15 medium or one containing $10 \mu \mathrm{M}$ Y27632 (T=0). Force measurements were continued for $90 \mathrm{~min}$ from this time point. 
Force measurements: Immediately after addition of melanoma cells into the endothelial cell-containing culture dish, before their attachment to the endothelium or the surface of the dish, a single melanoma cell was brought into contact with the very end of the cantilever in order to achieve the attachment between them. The position of the melanoma cell on the cantilever was monitored continuously during the experiment, and no considerable change occurred. The melanoma cell-containing cantilever was brought in contact with the endothelial monolayer with a frequency of $0.033 \mathrm{~Hz}$. The travel speed of the "cell probe" was set to $2 \mu \mathrm{m} / \mathrm{s}$ both for lowering (trace) and for pulling back (retrace). The total loading force applied was $2 \mathrm{nN}$. The intercellular adhesion forces were determined from the retrace curves by calculating the relative level difference between the maximal downward deflection of the cantilever and its alignment after total unbinding (Figure 3). As described previously (Vegh et al. 2012), the total adhesion force consists of elementary forces, which present as stair-like jumps on the retraction (retrace) phase of the force curve (Figure 3, inset).

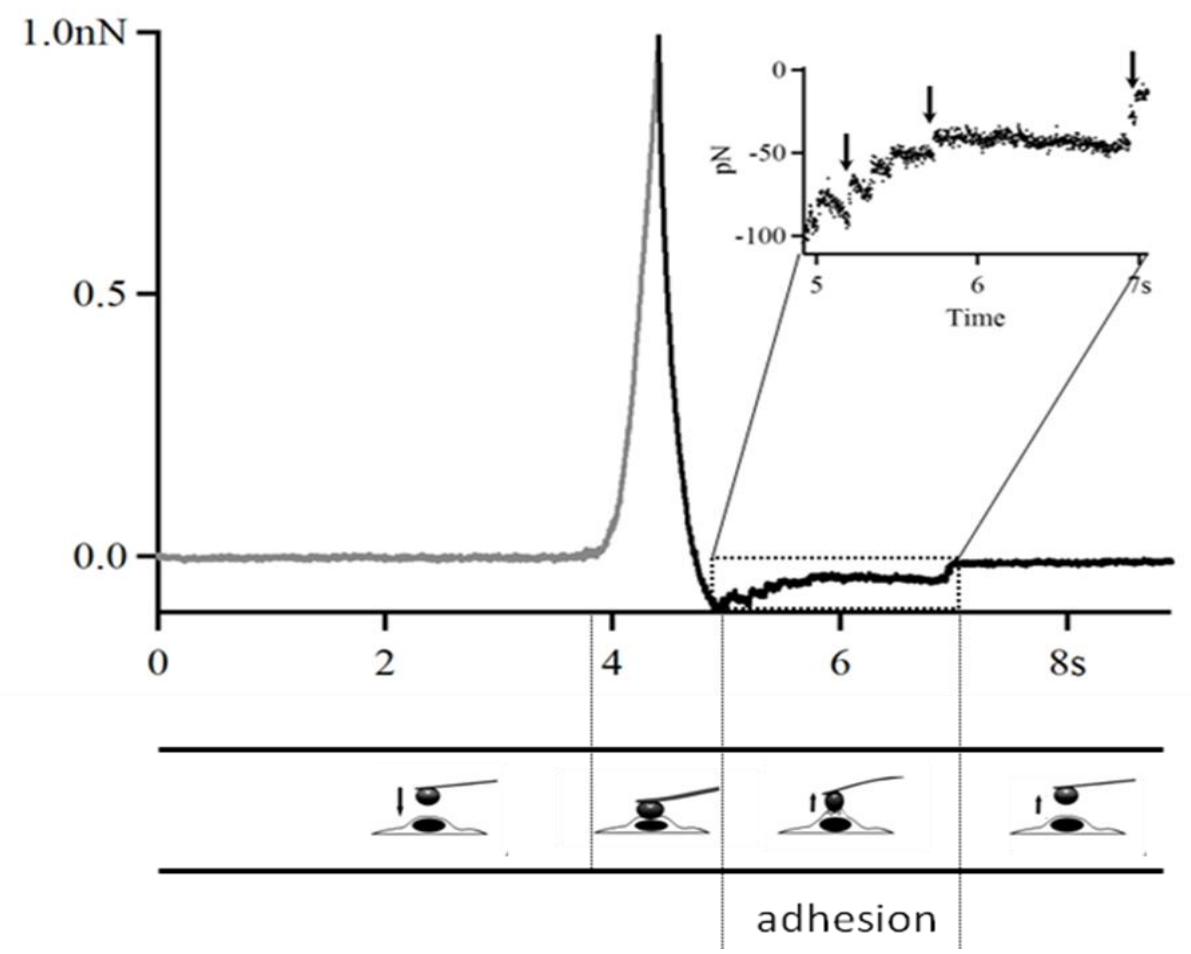

Figure 3: Measurement of adhesion forces using atomic force microscopy. Force curve (force vs. measurement time) of melanoma-endothelial interaction. Trace is plotted with grey and retrace is shown in black. The insert shows stair-like ruptures representing the elementary forces of the total adhesion force (top). Schematic representation of the position of the endothelium, the melanoma cellcontaining cantilever and the direction of the movement of the cantilever (arrow) (bottom). 
A homemade MatLab (MathWorks) routine was developed to extract total adhesion force values, and statistics to quantify the number and average size of stair-like jumps. Individual jumps on retract curves were identified as the level difference between two adjacent points passing a threshold. Two fold of the standard deviation taken from the last 50 points of each curve was given as threshold. Ten forces were recorded for each load (respectively dwell time) starting from low up to high values successively, followed by reverse direction recording from high to low values. Finally, the averages and standard deviations of corresponding values were calculated, and presented. Using this technique we eliminated the possible tip-induced alterations of applying unidirectional variation of load and dwell time.

\subsection{Immunofluorescence and phalloidin staining of the actin- cytoskeleton}

RBECs (P0 or P1) were cultured until confluence on collagen/fibronectin-coated glass coverslips. Melanoma cells (A2058 or B16/F10) were fluorescently labeled using CellTrackerTM Blue CMAC (Invitrogen) or OG and plated onto the endothelial monolayer. After $5 \mathrm{~h}$ cells were washed and fixed with ethanol/acetic acid. After blocking with 3\% BSA (Sigma) for $30 \mathrm{~min}$, coverslips were incubated with primary antibodies against occludin, claudin-5 or ZO-1 (Zymed) or cleaved caspase-3 (Cell Signaling). The staining was visualized using $\mathrm{Cy} 3$ - or Cy5-conjugated secondary antibodies. In apoptosis studies number of cleaved caspase-3 positive endothelial cells was compared to the total EC number. Three-dimensional optical sectioning was performed using an Olympus Fluoview FV1000 confocal laser-scanning microscope with spectral detectors. Using the Olympus Fluoview software (version 1.7.2.2), OG and Cy3 images were pseudocolored green and red, respectively.

Melanoma cells cultured alone on glass coverslips were fixed with $4 \%$ formaldehyde and permeabilized using acetone at $-20^{\circ} \mathrm{C}$ for $10 \mathrm{~min}$. After blocking cells were stained with Alexa488-phalloidin (LifeTechnologies). Mounting was performed in anti-fading embedding medium (Biomeda) and the distribution of the signal was studied using a Nikon Eclipse TE2000U photomicroscope with epifluorescent capabilities connected to a digital camera (Spot RT KE). 


\subsection{Measurement of transendothelial electrical resistance (TEER)}

RBECs were grown on collagen/fibronectin-coated semipermeable filters $(0.4 \mu \mathrm{m}$ pore size, $1.12 \mathrm{~cm}^{2}$, Costar Corning Transwell Clear). After reaching confluency, the endothelial monolayer was supplied with $550 \mathrm{nM}$ hydrocortisone, $250 \mu \mathrm{M}$ CPT-cAMP (Sigma) and 17.5 $\mu \mathrm{M}$ RO-201724 (Roche) and placed into the wells of the CellZscope ${ }^{\circledR}$ instrument (nanoAnalytics) containing astrocyte conditioned medium. After TEER had reached plateau, $10^{5}$ melanoma cells were plated into the apical chamber and TEER was followed for $24 \mathrm{~h}$.

\subsection{Transmigration experimental setup}

For transmigration experiments, primary RBECs were gently trypsinized and passed onto fibronectin/collagen-coated filter inserts $\left(8 \mu \mathrm{m}\right.$ pore size, $1.13 \mathrm{~cm}^{2}$, Millipore) which were placed in 12-well plates.

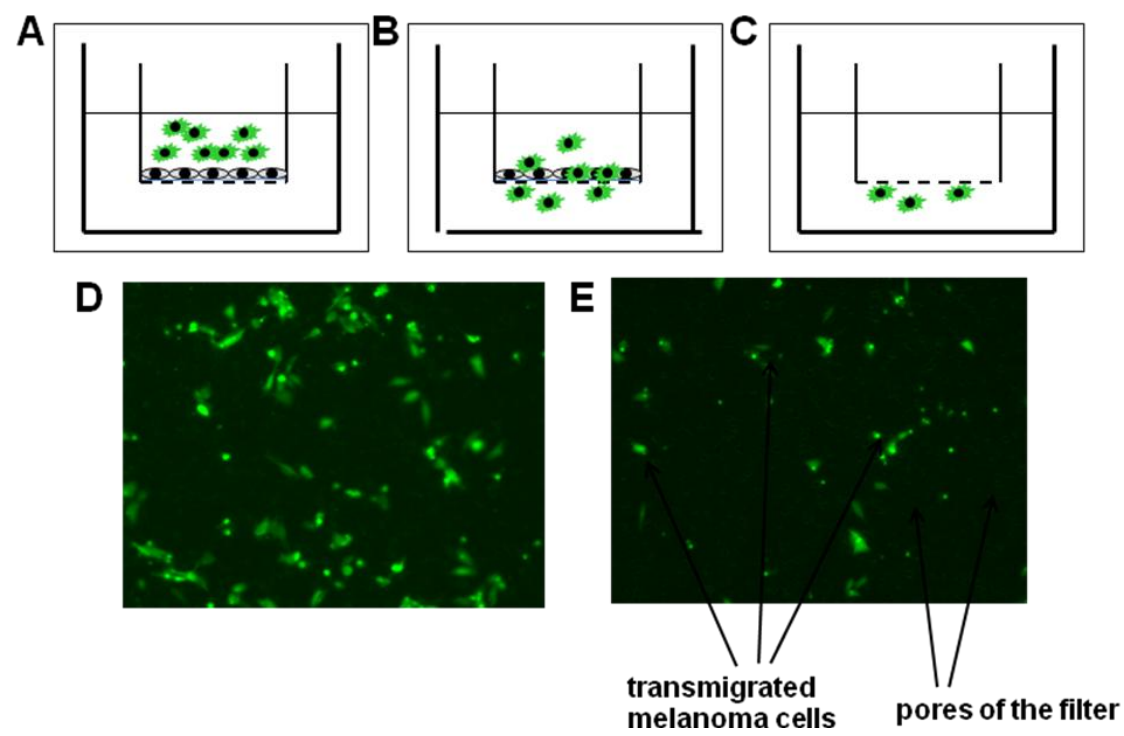

Figure 4: Use of the in vitro model for brain metastasis investigations. Fluorescently labeled cancer cells were plated on confluent endothelial cultures (A). At the end of the co-culture (B) cells from the upper compartment were removed $(C)$. Fluorescence microscopy images of the A2058 melanoma cells at the end of co-culture (D) and after wiping off the cells from the apical side of the filter (transmigrated cells, E). 
After reaching confluency, endothelial cells were supplemented with $550 \mathrm{nM}$ hydrocortisone, $250 \mu \mathrm{M}$ CPT-cAMP (Sigma) and 17.5 $\mu \mathrm{M}$ RO-201724 (Roche) from the apical side and astrocyte conditioned medium from the basolateral side for $24 \mathrm{~h}$ in order to tighten the junctions. $10^{5}$ OG-labeled melanoma cells were plated into the upper compartment onto the endothelial monolayer in serum-free medium. The lower compartment was loaded with serum-free medium containing $100 \mu \mathrm{g} / \mathrm{ml}$ type I collagen. Pefabloc $^{\circledR}(200 \mu \mathrm{M})$ or Y27632 $(10 \mu \mathrm{M})$ was added to both the apical and basolateral side. Cells were left for $5 \mathrm{~h}$, followed by fixation with ethanol/acetic acid. Cells from the upper compartment were removed with a cotton swab and melanoma cells migrated through the endothelial monolayer and through the pores of the filter were counted (Figure 4).

\subsection{Western-blot analysis}

Melanoma cells were plated onto confluent brain endothelial cells (RBEC or D3) in serum-free medium and left for $24 \mathrm{~h}$. Cells were washed with PBS and scraped into ice-cold lysis buffer $(20 \mathrm{mM}$ Tris, $150 \mathrm{mM} \mathrm{NaCl}, 0.5 \%$ Triton $\mathrm{X}-100,1 \%$ sodium deoxycholate, $0.1 \%$ sodium dodecyl sulphate, $1 \mathrm{mM}$ sodium vanadate, $10 \mathrm{mM} \mathrm{NaF}, 1$ $\mathrm{mM}$ EDTA, $1 \mathrm{mM}$ Pefabloc ${ }^{\circledR}$ ) and incubated on ice for $30 \mathrm{~min}$. Lysates were clarified by centrifugation at $10,000 \bullet \mathrm{g}$ for $10 \mathrm{~min}$ at $4^{\circ} \mathrm{C}$. Proteins were electrophoresed and blotted onto PVDF (Millipore) or nitrocellulose (Whatman) membranes. Blocking the nonspecific binding capacity of the membranes was carried out at room temperature for $30 \mathrm{~min}$ in TBS-T containing either $5 \%$ casein (nonfat milk powder) or $3 \%$ BSA in the case of claudin-5. Anti-claudin-5 (Zymed) and anti-occludin (Transduction Laboratories) primary antibodies were used. After washing the membranes in TBS-T, blots were incubated with the secondary antibodies (Pierce) diluted in TBS-T. The immunoreaction was visualized using the Immobilon Western Chemiluminescent HRP Substrate (Millipore) on X-ray film (Agfa).

\subsection{Zymography}

D3 cells were grown in 12-well plates. $2 \cdot 10^{5}$ A2058 melanoma cells were plated onto the endothelial monolayer in serum-free medium and left for $5 \mathrm{~h}$. Culture media 
were collected, clarified by centrifugation at $10,000 \cdot \mathrm{g}$ for $10 \mathrm{~min}$ on $4^{\circ} \mathrm{C}$ and prepared in mercaptoethanol-free Laemmli buffer. Cells were washed and lysed in ice cold TBS containing $1.5 \%$ Triton $\mathrm{X}-114$. Samples were centrifuged at $4^{\circ} \mathrm{C}$ and the supernatants were placed to $37^{\circ} \mathrm{C}$ for $5 \mathrm{~min}$. After centrifugation at room temperature for $2 \mathrm{~min}$ the upper aqueous phase was thrown away and the membrane fraction was dissolved in mercaptoethanol-free Laemmli buffer. Samples were electrophoresed under nondenaturing conditions in a polyacrylamide gel containing $1.5 \mathrm{mg} / \mathrm{ml}$ gelatin. Gels were washed two times in $2.5 \%$ Triton X-100 and two times in water and incubated for two days at $37^{\circ} \mathrm{C}$ in a buffer containing $50 \mathrm{mM}$ Tris $\mathrm{pH}=7.4,5 \mathrm{mM} \mathrm{CaCl}_{2}, 1 \mathrm{mM} \mathrm{ZnSO}_{4}, 1$ $\mathrm{mM} \mathrm{MgCl}_{2}$ and $0.2 \mathrm{M} \mathrm{NaCl}$ or $50 \mathrm{mM}$ Tris $\mathrm{pH}=7.4,0.2 \mathrm{M} \mathrm{NaCl}$ and $5 \mathrm{mM}$ EDTA. Gels were stained with Coomassie BBR-250 for 20 min and destained using $10 \%$ methanol and $10 \%$ acetic acid until the gelatinolytic bands became visible.

\subsection{Silencing by RNA interference}

Stealth $^{\mathrm{TM}}$ siRNA duplex oligoribonucleotides were designed using Life Technologies BLOCK-iT ${ }^{\mathrm{TM}}$ RNAi designer and were purchased from Life Technologies. The sequences used are summarized in Table 1. A2058 cells were plated at 50\% confluency. Transfection of oligonucleotides was performed in OptiMEM medium (Life Technologies) containing $20 \mathrm{nM}$ RNA and DharmaFECT4 transfection reagent (Thermo Scientific) following the manufacturer's instructions when ROCK I-II were silenced. Specific knock-down of seprase was performed in OptiMEM medium containing $10 \mathrm{nM}$ RNA and Lipofectamine ${ }^{\mathrm{TM}}$ RNAiMAX reagent (Invitrogen) following the manufacturer's instructions. After $8 \mathrm{~h}$ the medium was changed to regular culture medium. In order to increase the efficiency, a second transfection was performed the following day. Cells were used $24 \mathrm{~h}$ after the second transfection. At the same time transfection efficiency was analyzed by real-time PCR. 


\begin{tabular}{|c|c|c|}
\hline \multirow{2}{*}{ Name } & & Sequence (5' -3') \\
\hline \multirow{2}{*}{ ROCK I } & sense & UAGAGUGUCGAAGAUGCCAUGUUAA \\
\cline { 2 - 3 } & antisense & UUAACAUGGCAUCUUCGACACUCUA \\
\hline \multirow{2}{*}{ ROCK II } & sense & CCGUUGCCAUAUUAAGUGUCAUAAA \\
\cline { 2 - 3 } & antisense & UUUAUGACACUUAAUAUGGCAACGG \\
\hline \multirow{2}{*}{ Seprase } & sense & AAGAAGUGUGUUACUUGCCAUCUAA \\
\cline { 2 - 3 } & antisense & UUAGAUGGCAAGUAACACACUUCUU \\
\hline \multirow{2}{*}{ Control } & sense & GACGUAGAGAGAGUUCCGACAUACA \\
\cline { 2 - 3 } & antisense & UGUAUGUCGGAACUCUCUCUACGUC \\
\hline
\end{tabular}

Table 1: Stealth siRNA sequences used for silencing of ROCK-I, -II and seprase.

\subsection{Evaluation of brain metastasis formation in vivo}

7-10 week old C57BL/6 male mice were anaesthetized with Avertin (Fluka) administered intraperitoneally $(30 \mathrm{mg} / 100 \mathrm{~g}$ body weight in a volume of $0.35 \mathrm{ml}) \cdot 10^{6}$ B16/F10 melanoma cells were injected in $200 \mu$ Ringer-HEPES solution into the right common carotid artery using a syringe with a 30-gauge needle. Following inoculation of tumor cells $500 \mu \mathrm{g} / \mathrm{kg}$ Y27632 was administered intravenously to some animals. After 10 days animals were sacrificed (terminal anaesthesia with Avertin), transcardially perfused with phosphate buffered saline (PBS, $10 \mathrm{mM}, \mathrm{pH}=7.4$ ), followed by $3.5 \%$ paraformaldehyde (Sigma) in PBS. Brains were removed and placed into the same fixative overnight at $4^{\circ} \mathrm{C}$. After postfixation brains were cryoprotected in $30 \%$ sucrose (in $10 \mathrm{mM}$ PBS) for at least 2 days at $4^{\circ} \mathrm{C} .50 \mu \mathrm{m}$ cryosections were prepared and melanotic lesions were counted. Only parenchymal metastases (at a distance of at least $500 \mu \mathrm{m}$ from the meninges and ventricles) were considered. All mice were housed and treated in accordance with widely accepted standards and the protocols were approved by the institutional care and the regional committee for animal research. 


\section{Results}

\subsection{Interaction of melanoma cells with the in vitro BBB model: adhesion and transmigration}

In the process of brain metastasis formation, the ability of tumor cells to adhere to cerebral endothelial cells has a critical role. To assess metastatic melanoma cells' adhesion ability we employed an in vitro model of the blood-brain barrier. Melanoma cells were seeded onto confluent cerebral endothelial cells (D3 or RBEC). We observed that both A2058 and B16/F10 melanoma cells were able to adhere to endothelial cells. In our experimental setup, we observed that melanoma cells started to attach to endothelial monolayers early, approximately $15 \mathrm{~min}$ after seeding. The number of adherent melanoma cells increased in time (Figure 5).

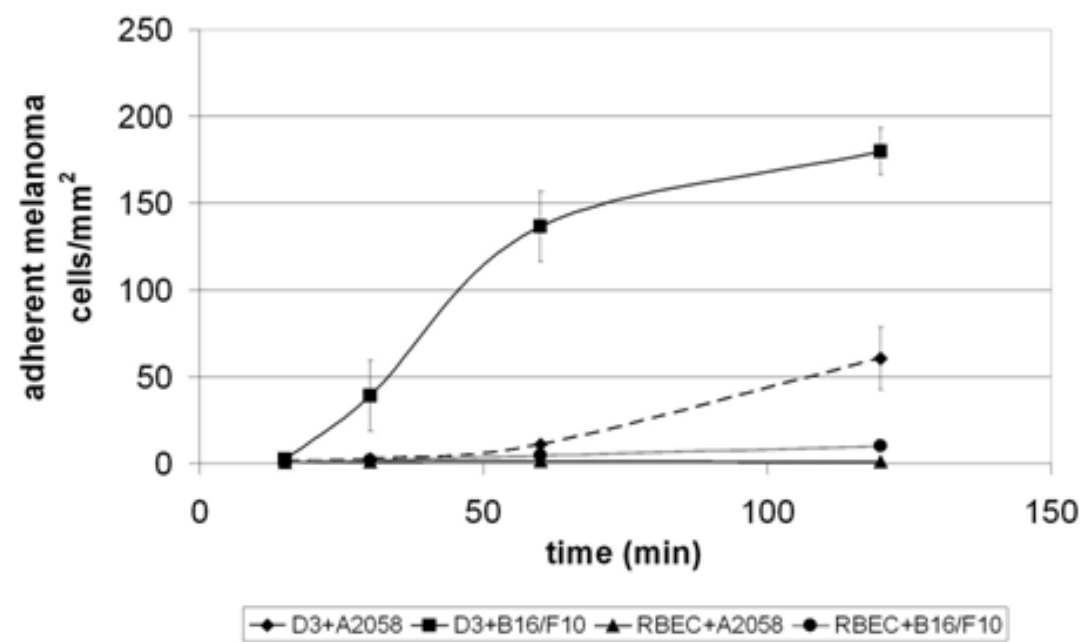

Figure 5: Adhesion of melanoma cells to brain endothelial cells. Fluorescently labeled melanoma cells (A2058 or B16/F10) $\left(2.5 \cdot 10^{4} / \mathrm{cm}^{2}\right)$ were plated onto confluent CECs (RBEC or D3) and left for different time intervals. After washing of non-adherent cells, attached melanoma cells were counted.

When parallely the same numbers of A2058 or B16/F10 cells were plated onto confluent brain endothelial monolayers, B16/F10 cells attached in a higher number to the 
endothelium than A2058 cells. Comparing the two endothelial monolayers, both melanoma cell types adhered much easier to the human cell line than to primary rat cells.

Attachment of melanoma cells to endothelial cells precedes their penetration beneath the endothelial monolayer. Indeed, in our transmigration experiments melanoma cells were able to migrate through CECs. The transendothelial migration of melanoma cells could be visualized by z-stack laser confocal microscopy images. Endothelial cells were grown on coverslips and melanoma cells were plated onto the apical (luminal) side of the monolayer ("above" endothelial cells). The cellular processes extended by melanoma cells reaching the basolateral side of endothelial cells could be observed closer to the coverslip than the tight junctions of endothelial cells ("beneath" endothelial cells) (Figure 6).

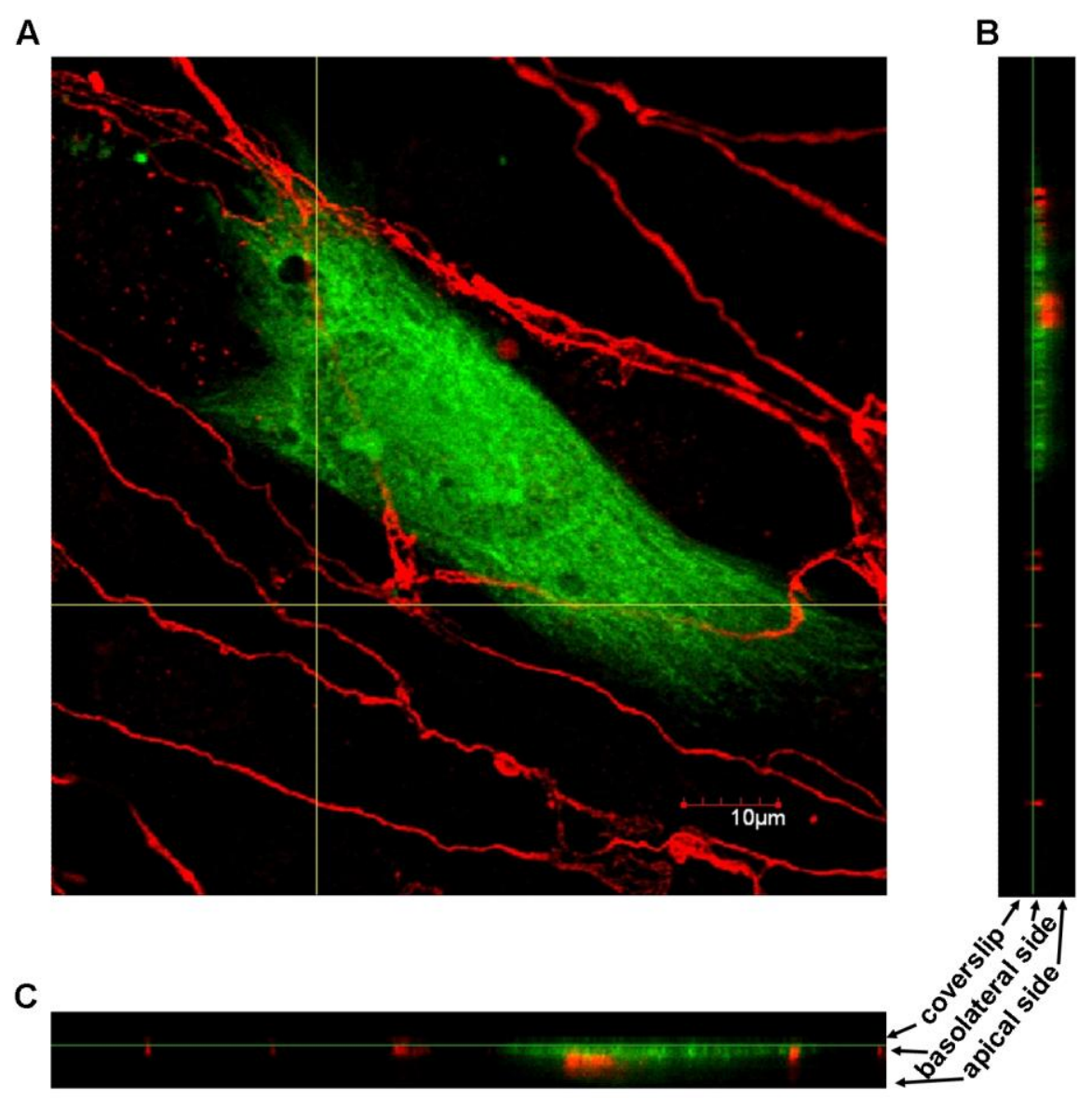

Figure 6: Migration of melanoma cells from the apical to the basolateral side of CECs. RBECs were grown on glass coverslips. A2058 melanoma cells labeled with OG (green cell) were plated onto confluent endothelial monolayers. After $5 \mathrm{~h}$ cells were washed, fixed and tight junctions were stained with anti-ZO-1 antibody (red). Samples were analysed by confocal laser scanning microscopy. A: xystack at the level of the green lines on B and C. B, C: z-stacks along the vertical and horizontal line, respectively on $\mathrm{A}$. 


\subsection{Effects of melanoma transmigration on BBB integrity}

\subsubsection{Melanoma cells impair the integrity of endothelial barrier}

The appearance of melanoma protrusions beneath the endothelial monolayer led us to investigate how the presence of melanoma cells affects the integrity of the endothelial barrier. The barrier properties of endothelial monolayers can be determined by the measurement of transendothelial electrical resistance (TEER). $5 \mathrm{~h}$ after seeding of melanoma cells, the more invasive B16/F10 already reduced the TEER values of CECs. In the case of A2058 we observed a time dependent fall in the endothelial resistance, to a decrease reaching $30 \%$ at $24 \mathrm{~h}$ (Figure 7).

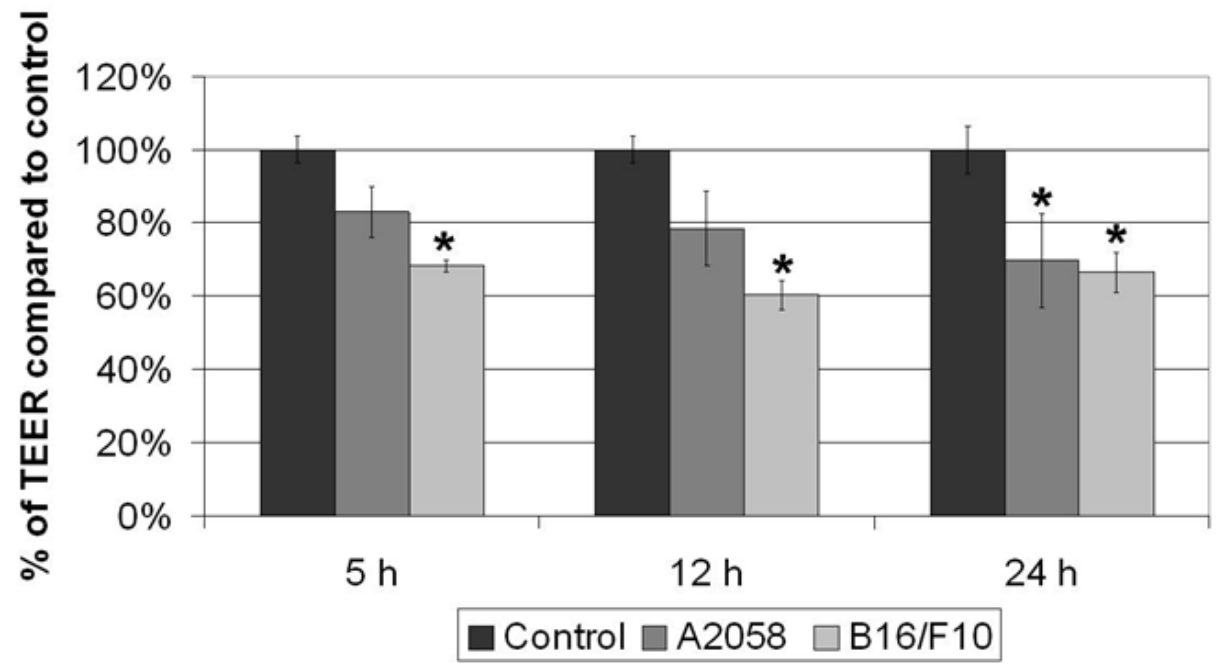

Figure 7: Changes in the transendothelial electrical resistance in the presence of melanoma cells. RBECs were grown on semipermeable filters with $0.4 \mu \mathrm{m}$ pore size. TEER was followed using the CellZscope system. $\mathbf{N}=2, *=\mathbf{P}<0.05$ as assessed by ANOVA and Bonferroni's post hoc test.

4.2.2 Paracellular transmigration of melanoma cells induces disassembly of endothelial tight junctions

Regarding the path of transmigration much of our knowledge comes from experiments with leukocytes, which are able to transmigrate both between (paracellularly) and through (transcellularly) endothelial cells. The paracellular space between adjacent ECs is sealed by tight junctions. The drop in the transendothelial electrical resistance of the cells indicated a possible damage of the junctional complex. Therefore, in our 
experiments we have focused on the investigation of the paracellular migration of melanoma cells.

Hence, we have examined changes in the localization and expression of the main tight junction proteins. Figure 8 shows that melanoma cells tended to adhere to brain endothelial cells in small clusters and were able to disrupt the continuous membrane staining of transmembrane TJ proteins (occludin and claudin-5), and the cytoplasmic plaque protein ZO-1. As shown in Figure 8, panel A, the first affected TJ proteins were transmembrane proteins, since claudin-5 disappeared totally at $2 \mathrm{~h}$ co-culture from the same place where ZO-1 staining was only partly disrupted. At $5 \mathrm{~h}$ after plating of melanoma cells onto CECs, no difference was observed between the localization changes of the different junctional proteins. Small clusters of A2058 cells adhered to CECs induced the disappearance of claudin-5, ZO-1 (Figure 8, panel B) and occludin (Figure 8, panel C) from the intercellular contacts. We could observe the same phenomenon in case of B16/F10 cells (Figure 8, panel D).

These results suggest that melanoma cells are able to take the paracellular pathway of transmigration. This was also supported by our Western-blot experiments (Figure 9). As expected, neither A2058 nor B16/F10 cells expressed claudin-5 or occludin, which were present in both RBEC and D3 brain endothelial cells. The claudin-5 signal was strongly decreased by both melanoma cell lines in RBECs (Figure 9, panel A) and disappeared completely from D3 cells (Figure 9, panel B), while melanoma conditioned media induced a less pronounced effect. Similar tendencies could be observed in case of occludin (Figure 9, panel C and D), where the degradation products could also be visualized in D3 cells in the presence of B16/F10 cells or conditioned medium (Figure 9, panel D). 
A
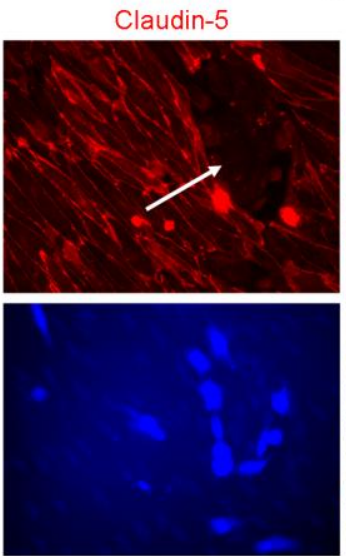

A2058 melanoma
$\mathrm{ZO}-1$
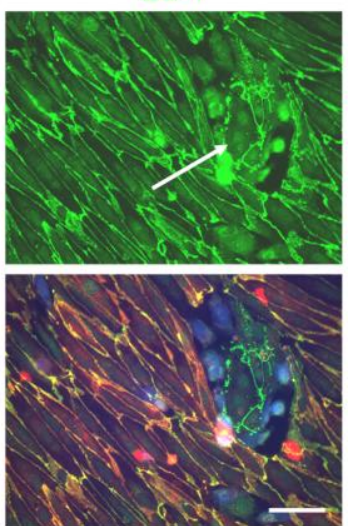

merged image

$2 \mathrm{~h}$

C
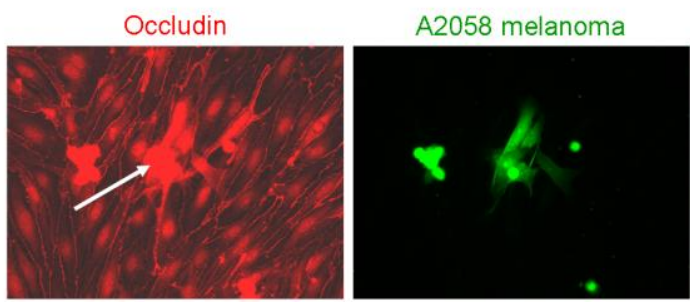

$5 \mathrm{~h}$

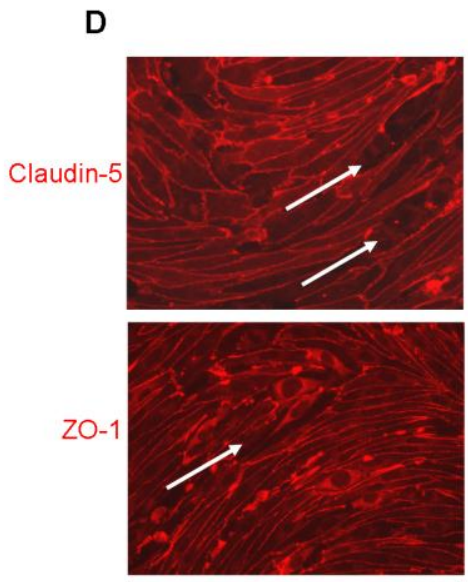

B16/F10 melanoma
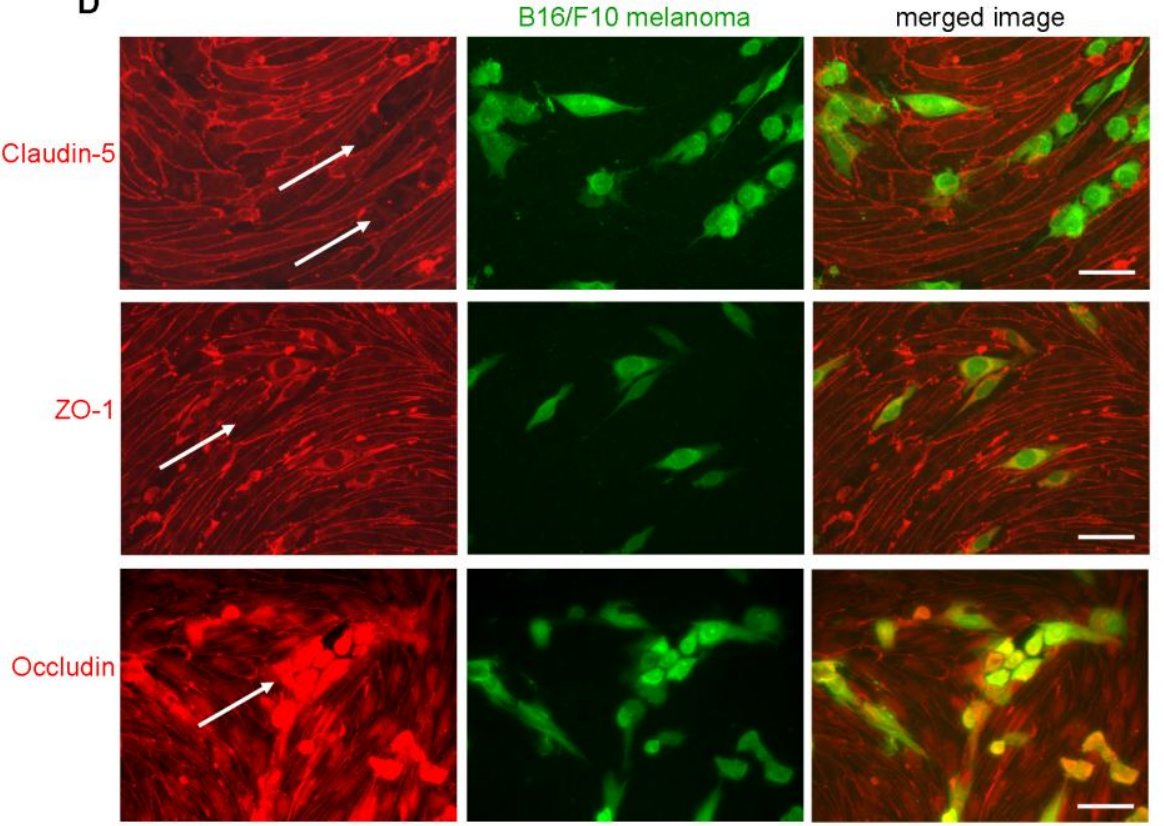

Claudin-5
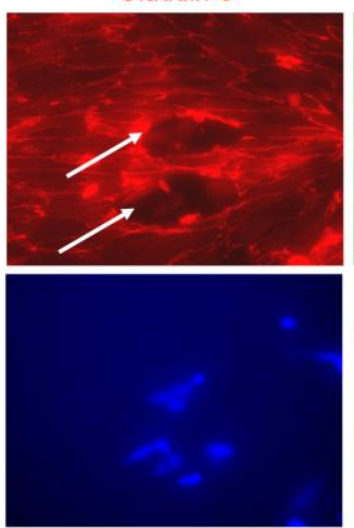

A2058 melanoma
B
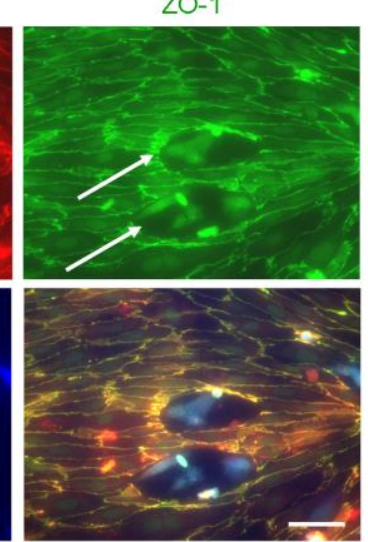

$5 \mathrm{~h}$

merged image
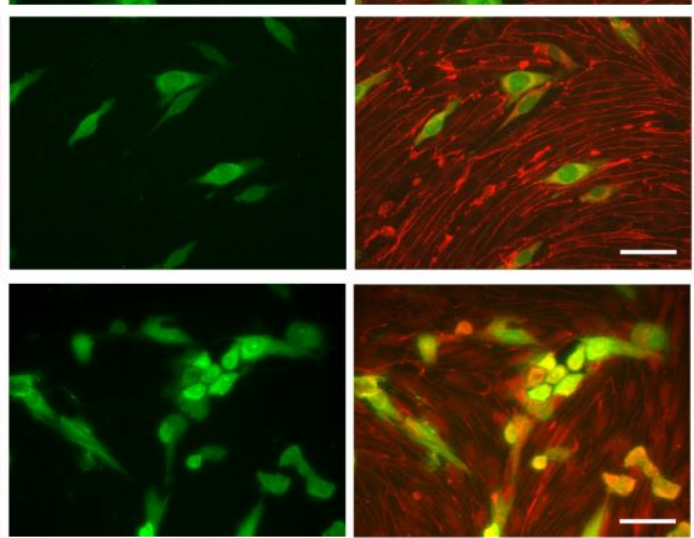

$5 \mathrm{~h}$

Figure 8: Disruption of interendothelial tight junctions induced by melanoma cells. Fluorescently labeled (A, B: CellTrackerTM Blue, C, D: OG) melanoma cells (A, B, C: A2058 or D: B16/F10) were plated onto confluent brain endothelial cells (RBECs) and left for 2 (A) or $5 \mathrm{~h}$ (B-D). After washing of non-attached melanoma cells samples were fixed and stained for claudin-5, ZO-1 or occludin. Arrows indicate sites of disrupted junctions. Scale bar $=50 \mu \mathrm{m}$. 


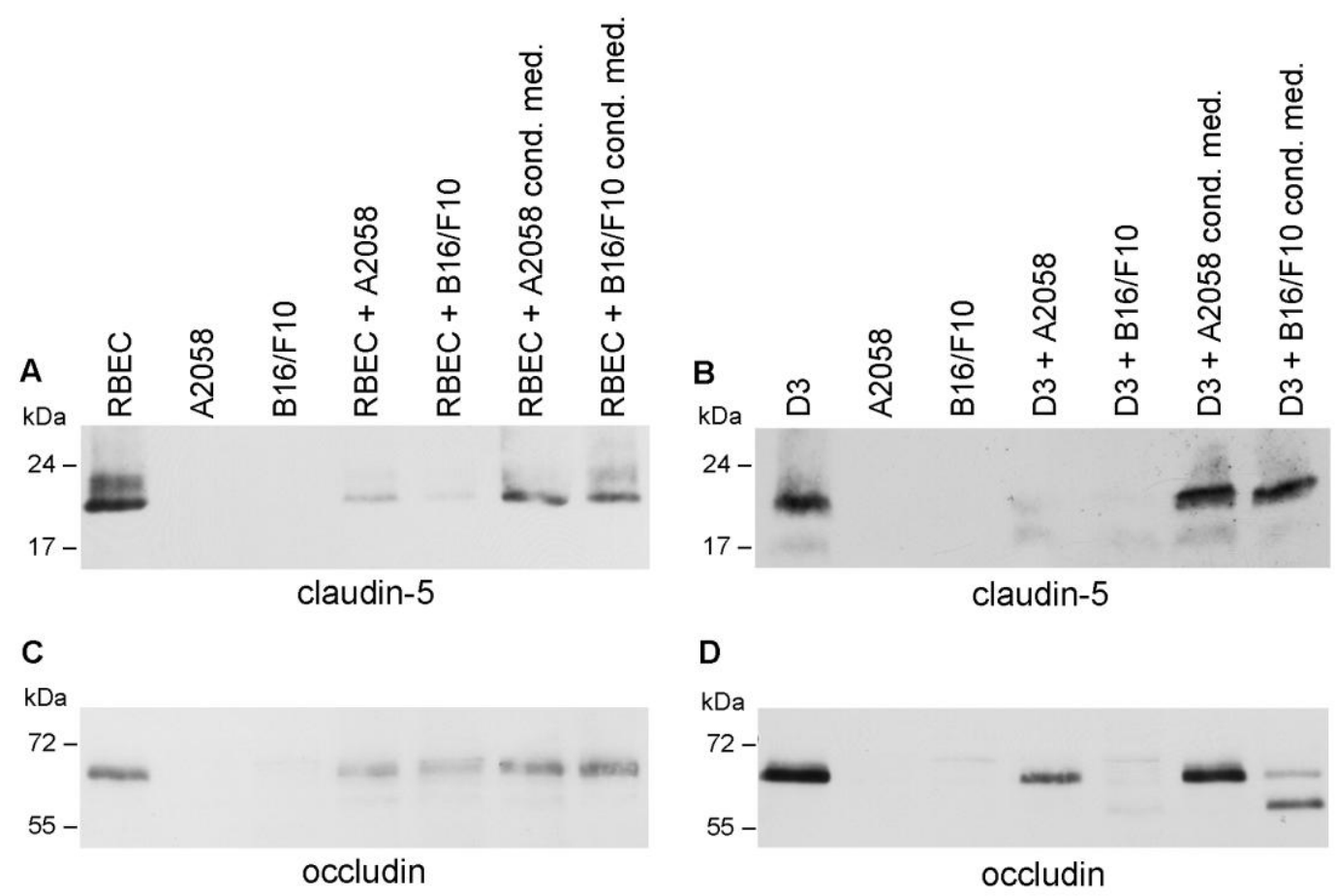

Figure 9: Changes in the total amount of endothelial junctional proteins in the presence of melanoma cells or melanoma-released factors. Melanoma cells or melanoma conditioned media were placed onto confluent brain endothelial cells (A, C: RBEC; B, D: D3) and the amount of claudin-5 (A, B) or occludin $(C, D)$ was assessed by Western-blot analysis.

Our data underscore that melanoma cells are able to disrupt the junctions of CECs and transmigrate through the paracellular pathway.

4.2.3 Interaction between melanoma and cerebral endothelial cells induces EC apoptosis

Metastatic tumor cells may facilitate their extravasation not just by disrupting the cell-cell junctions but also by inducing endothelial apoptosis. Melanoma cells induced a 4.7 fold increase in the number of apoptotic brain endothelial cells (from $1.7 \%$ in the absence of A2058 cells to 7.54\%) as visualized by anti-cleaved caspase-3 staining (Figure 10). No difference in the number of apoptotic melanoma cells was observed in the presence or absence of CECs (not shown). 


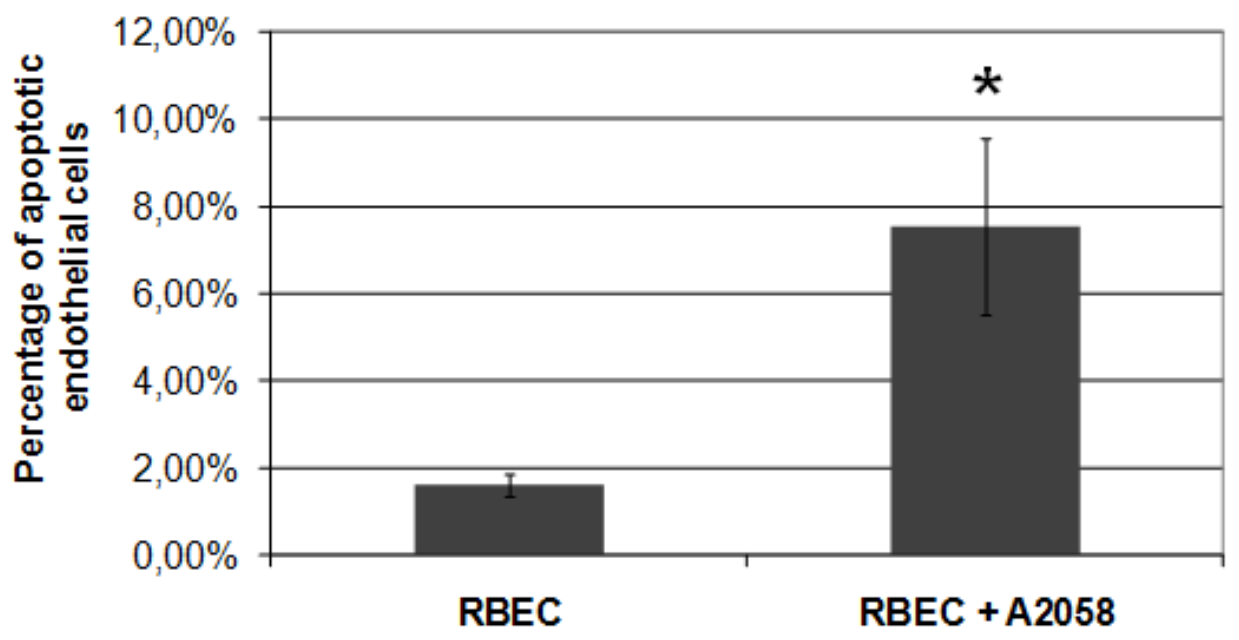

Figure 10: Induction of endothelial apoptosis by melanoma cells. RBECs were cultured on glass coverslips. A2058 melanoma cells labeled with CellTracker ${ }^{\text {TM }}$ Blue were plated onto confluent endothelial monolayers. After $24 \mathrm{~h}$ cells were washed and fixed. Tight junctions were stained with anti-ZO-1 antibody (marker of endothelial cells), while apoptotic cells were visualized using anticleaved caspase-3 antibody. Apoptotic endothelial cells were counted. $\mathrm{N}=2, *=\mathbf{P}<0.05$ as assessed by Student's t-test.

\subsection{Role of proteolysis in melanoma transmigration}

Expression and release of proteases during tumor cell migration has a critical role in the invasion of the host microenvironment. Endothelial cells encounter migrating melanoma cells, which may secrete proteases in order to facilitate their exravasation.

To address this phenomenon we have investigated the production of proteases by A2058 and B16/F10 melanoma cells in the presence and absence of brain endothelial cells by gelatin zymography. Proteolytic enzymes both released in the culture medium (Figure 11, panel A) and their membrane bound forms (Triton X-114 fraction) (not shown) were analyzed. We have observed that both melanoma cell lines expressed several gelatinolytic proteases and their amount increased when melanoma cells were plated onto brain endothelial cells. Unexpectedly, the gelatinolytic bands did not disappear in the presence of the matrix metalloproteinase inhibitor EDTA (Figure 11, panel A).

Addition of E-64, an irreversible, potent and highly selective cysteine protease inhibitor had no effect on the release of gelatinolytic enzymes. However, addition of Pefabloc $\AA$, an irreversible serine protease inhibitor to the cells, induced the almost 
complete disappearance of the proteolytic bands from both the supernatant and the cell lysate fraction. This indicates that gelatinolytic serine proteases are produced by melanoma cells in large amounts especially when coming in contact with endothelial cells.

We have also observed that presence of Pefabloc® significantly reduced the transendothelial migration rate of both A2058 (Figure 11, panel B) and B16/F10 melanoma cells (to $58 \% \pm 4 \%$ in case of A2058 and to $44 \% \pm 11 \%$ in case of B16/F10 (not shown)).

A

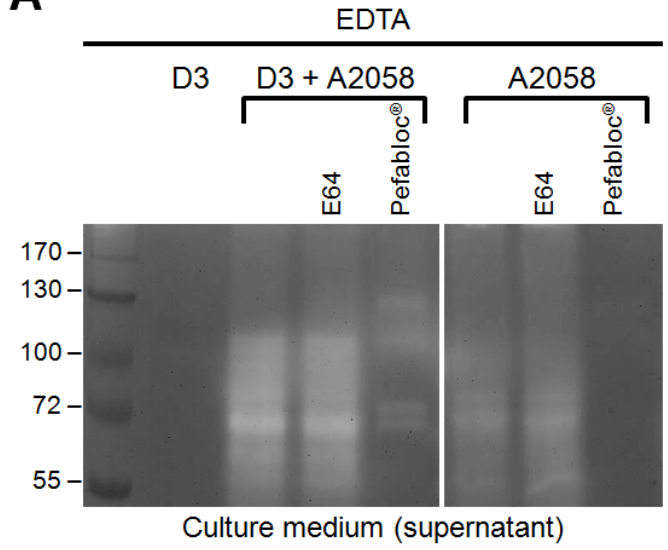

B

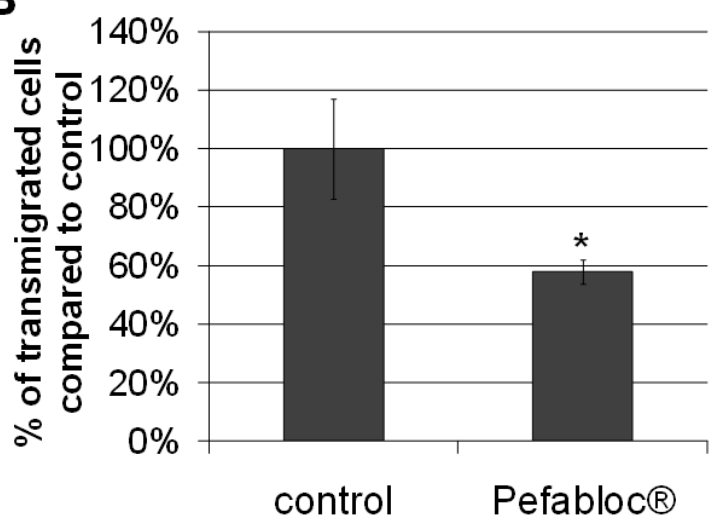

Figure 11: Role of gelatinolytic serine proteases produced by melanoma cells. A: Melanoma cells were plated onto confluent monolayers of cerebral endothelial cells or into empty culture dishes in serumfree medium in the presence or absence of E64 or Pefabloc $®$ and left for $5 \mathrm{~h}$. Culture media were collected, then samples were electrophoresed in non-denaturing conditions and the gels were incubated in EDTA-containing buffer for 2 days. Proteolytic bands of culture media (A) were visualized by Coomassie blue staining. B: RBECs were grown until confluency on $8 \mu \mathrm{m}$ pore size filter inserts. Fluorescently labeled A2058 melanoma cells were plated into the upper chamber in the presence or absence of Pefabloc ${ }^{\circledR}$ and left for $5 \mathrm{~h}$. Cells from the upper chamber were removed using a cotton swab, and melanoma cells migrated through the endothelial cell layer and the pores of the filter were counted. $\mathbf{N}=3, *=P<0.05$ as assessed by Student's t-test.

As a next step we wanted to identify which serine proteases were expressed by melanoma cells. One of the most well characterized serine protease with gelatinolytic activity is seprase. A2058 melanoma cells expressed a $170 \mathrm{kDa}$ gelatinolytic membranebound serine protease (Figure 12, panel A) in their cell membrane. After silencing of the seprase gene the $170 \mathrm{kDa}$ gelatinolytic band disappeared from the zymogram (Figure 12, panel A). Therefore, we could identify seprase as one of the gelatinolytic serine proteases expressed by A2058 cells. Silencing of seprase in A2058 melanoma cells induced a more than $20 \%$ decrease in the number of cells transmigrated through brain endothelial cells 
(Figure 12, panel B). These data suggest that seprase plays an important, but not a unique role among proteases involved in the transmigration of melanoma cells through the BBB.

A

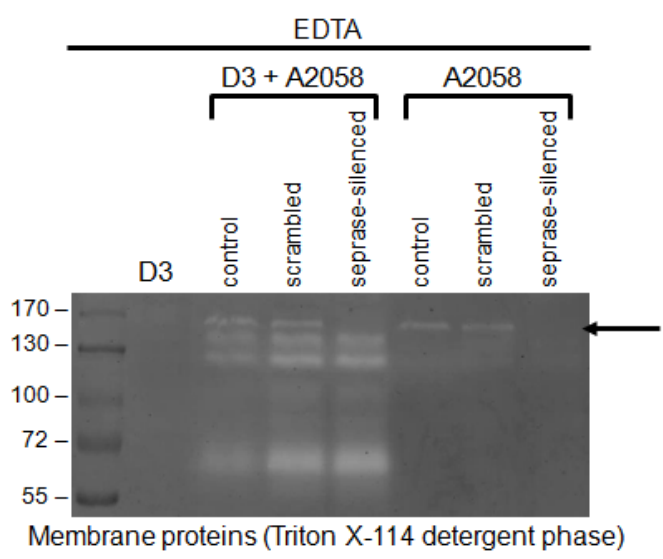

B

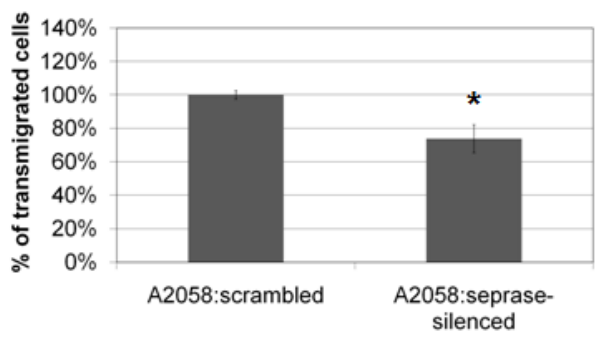

Figure 12: Role of seprase in the transmigration of $\mathbf{A 2 0 5 8}$ cells through brain endothelial cells. A: Seprase was silenced in A2058 cells (fold change $=\mathbf{0 . 0 9}$ compared to scrambled RNA-transfected cells, determined by real-time PCR). Melanoma cells were plated onto confluent monolayers of cerebral endothelial cells or into empty culture dishes in serum-free medium and left for 5 h. Cells were lysed in Triton X-114 containing buffer. Zymography was performed in the presence of EDTA. Arrow indicates seprase. B: Seprase-silenced or scrambled RNA-transfected A2058 cells were plated onto confluent RBECs grown on $8 \mu \mathrm{m}$ pore size filter inserts. Transmigration assay was performed and melanoma cells reaching the bottom of the filter inserts were counted. $\mathbf{N}=3, *=\mathbf{P}<0.05$ as assessed by Student's t-test.

The increased proteolytic activity of melanoma cells in the presence of endothelial cells implied that melanoma transmigration requires extracellular proteolysis. The mode of migration that involves proteases is Rac-driven, with low Rho-Rho kinase activity, known as mesenchymal movement. 


\subsection{Role of the Rho/ROCK signaling pathway in the transmigration of melanoma cells}

\subsubsection{Rho/ROCK inhibition fosters the mesenchymal phenotype of metastatic melanoma}

To elucidate the role of the mesenchymal phenotype in melanoma adhesion and transmigration we investigated the effect of ROCK inhibition on melanoma cell morphology. A2058 and B16/F10 were seeded onto collagen-coated coverslips in the presence or absence of Y27632. At 90 min after plating untreated cells had a rounded or slightly elongated morphology with several membrane blebs. Upon ROCK inhibition melanoma cells adopted an elongated, fibroblastoid morphology with actin-rich protrusions and several filopodia (Figure 13, panel A).
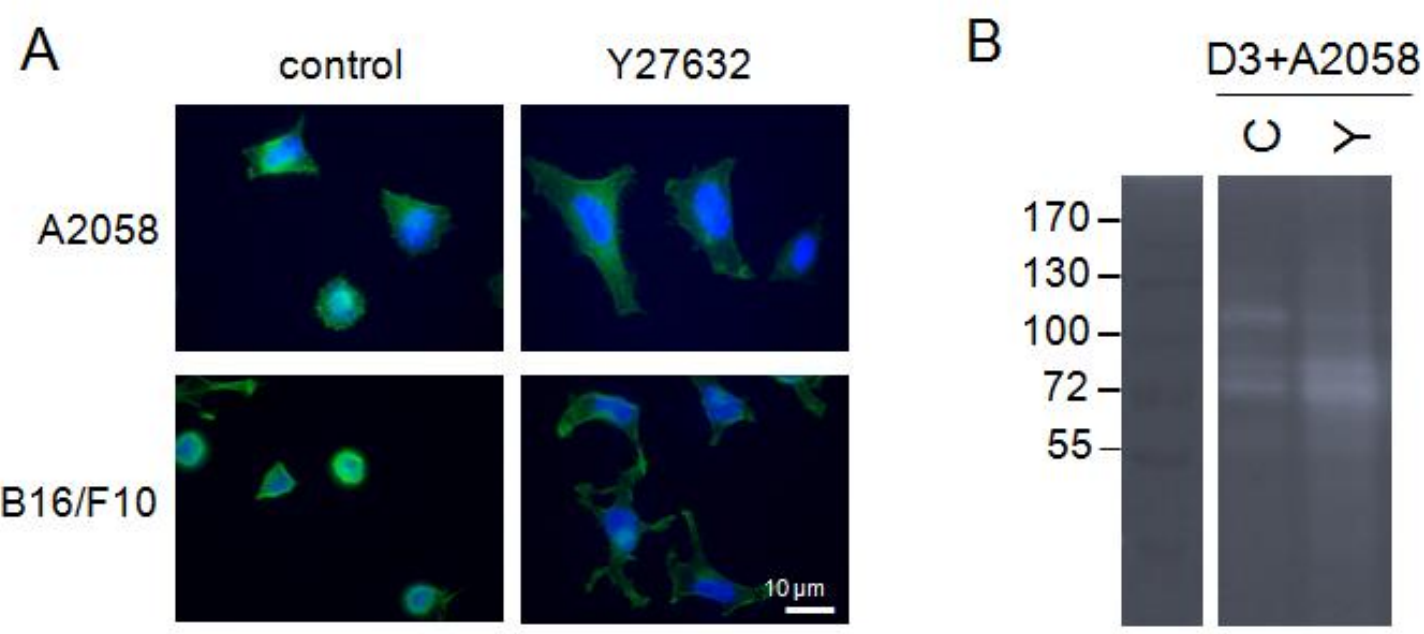

Figure 13: Effect of Y27632 on the morphology and protease activity of melanoma cells. A: A2058 or B16/F10 melanoma cells were seeded onto collagen-coated surfaces in the presence or absence of $10 \mu \mathrm{M}$ Y27632. After 90 min cells were fixed and stained with Alexa488-labeled phalloidin. B: A2058 melanoma cells were pretreated or not for 90 min with Y27632, then plated onto confluent monolayers of D3 cerebral endothelial cells in serum-free medium in the presence of Y27632 and left for $5 \mathrm{~h}$. Culture media (supernatants) were electrophoresed in non-denaturing conditions and the gels were incubated in EDTA-containing buffer for 2 days. Proteolytic bands of culture media were visualized by Coomassie blue staining. 
Moreover, the ROCK inhibitor Y27632 increased the proteolytic activity of melanoma cells (Figure 13, panel B). Inhibition of Rac, however, diminished the increase of proteolytic activity (not shown). These suggest that inhibition of ROCK induces a shift of melanoma cells to the mesenchymal type of morphology.

4.4.2 Mesenchymal phenotype of melanoma cells enhances their adhesion to the cerebral endothelium

As a next step we investigated the effect of the inhibition of ROCK on the attachment of melanoma cells to monolayers of cerebral endothelial cells. A2058 melanoma cells were seeded onto hCMEC/D3 (D3) endothelial monolayers in the presence or absence of $10 \mu \mathrm{M}$ Y27632 for $90 \mathrm{~min}$. Inhibition of ROCK led to a significant increase in the number of melanoma cells attached to the endothelium (Figure 14, panel A). In control conditions the ratio of elongated vs. rounded melanoma cells attached to the endothelium was 1.33, while in the presence of Y27632 a significant shift to the elongated morphology was observed (Figure 14, panel A).

Moreover, silencing of ROCK-I and ROCK-II genes in melanoma cells significantly increased their adhesion to the brain endothelium (Figure 14, panel B), supporting the role of the Rho/ROCK pathway in melanoma cells in the interaction between melanoma cells and brain endothelial cells. Inhibition of both ROCK-I and ROCK-II was needed to increase the adhesion of melanoma cells to the brain endothelium, since silencing of either ROCK-I or ROCK-II in melanoma cells induced only a slight, non-significant increase in the adhesion rate $(128.50 \% \pm 16.26 \%$ and $134.00 \% \pm 19.80 \%$, respectively, compared to control cells). 
A

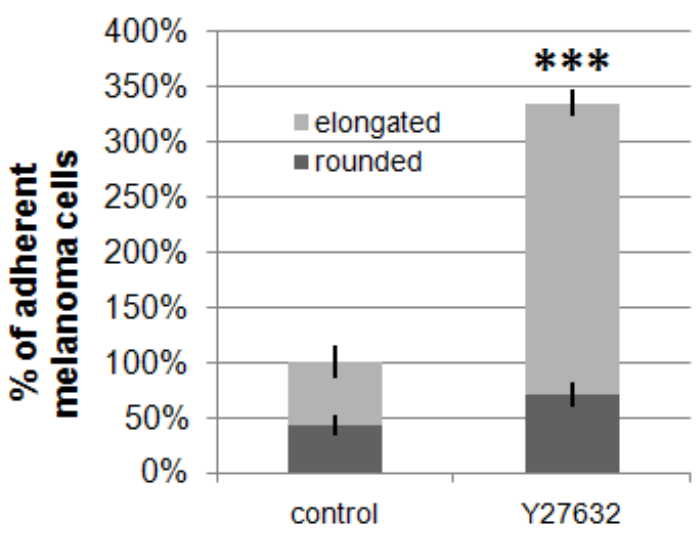

B

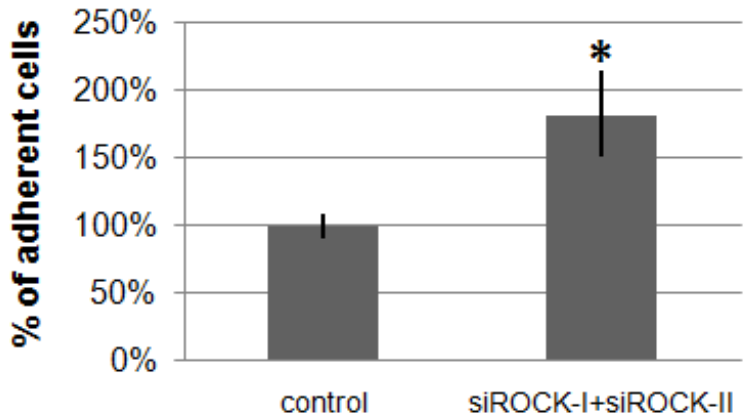

Figure 14: Effect of ROCK inhibition (Y27632 or ROCK-I and ROCK-II silencing) on the adhesion of melanoma cells onto brain endothelial cells. A: Fluorescently labeled A2058 melanoma cells were plated onto confluent D3 monolayers and left for 90 min. After washing of non-adherent cells, attached melanoma cells were counted. B: ROCK-I and ROCK-II genes were silenced in A2058 melanoma cells with an efficiency of $49 \%$ and $63 \%$, respectively, as assessed by real-time PCR. Melanoma cells were fluorescently labeled and plated onto confluent D3 monolayers for 90 min. After washing of non-adherent cells, attached melanoma cells were counted. Control = cells transfected with a non-targeting RNA duplex. Results are expressed as \% control and given as mean $\pm \mathrm{SD}$. $\mathbf{N}=3$, $* * *=\mathbf{P}<0.0005, *=\mathbf{P}<0.05$ as assessed by Student's t-test.

\subsubsection{Rho-kinase inhibition increases the adhesion forces between} melanoma cells and endothelial cells

We were interested whether there is a correlation between increased number of attached melanoma cells to endothelium and the adhesion forces between individual melanoma cells and endothelial cells. Therefore, we performed single-cell force spectroscopy measurements.

Melanoma cells were immobilized to the very edge of functionalized tipless atomic force microscope (AFM) cantilevers and we quantified the total unbinding force (adhesion) between the melanoma cell and the endothelial layer. 


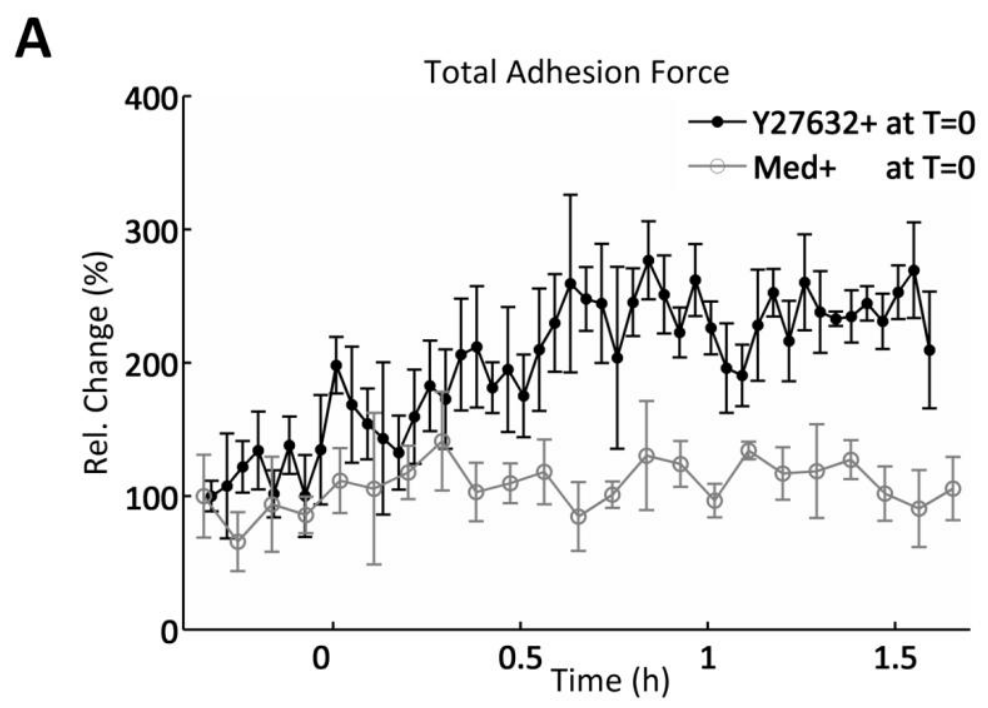

B

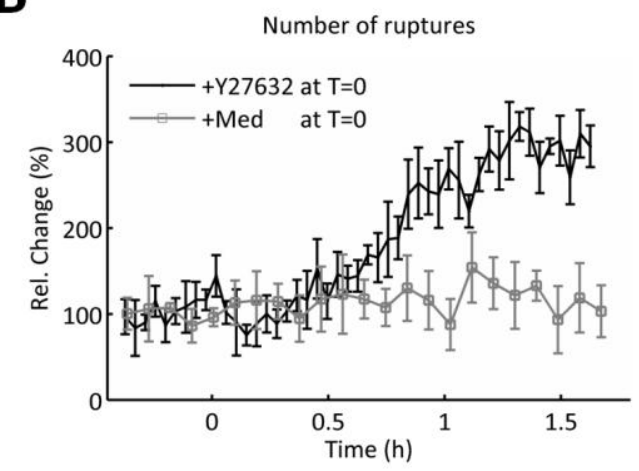

C

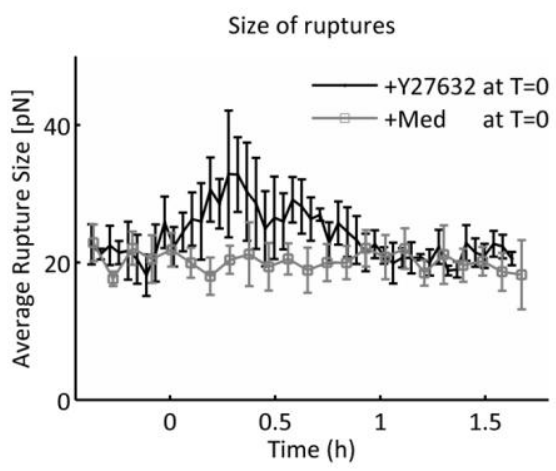

Figure 15: Measurement of melanoma-endothelial adhesion force using AFM. Fluorescently labeled A2058 melanoma cells were attached to functionalized tipless AFM cantilevers and pressed against a D3 endothelial layer. The adhesion force was quantified as described in the Material and methods. At $\mathrm{T}=0$ fresh medium was added containing or not $10 \mu \mathrm{M}$ Y27632. A: total adhesion force, B: number of ruptures, $\mathrm{C}$ : size of ruptures. Results are expressed as \% control and given as mean $\pm \mathrm{SD}, \mathrm{N}=5$.

When a loading force of $2 \mathrm{nN}$ was applied the total adhesion force was of $200 \mathrm{pN}$ in control conditions. We found that inhibition of ROCK led to an increase in the total unbinding force between melanoma and endothelial cells, reaching an approximately 2.5fold value after 45 min (Figure 15, panel A). Initially the size and later the number of individual unbinding events seemed to increase (Figure 15, panel B and C). 
4.4.4 ROCK inhibition raises the transmigration rate of melanoma cells through CECs

The above presented experiments clearly showed that ROCK inhibition of melanoma cells was associated with an increase in the adhesion force and in the number of adherent cells. We wondered whether this was accompanied by an increase in the number of transmigrating melanoma cells.

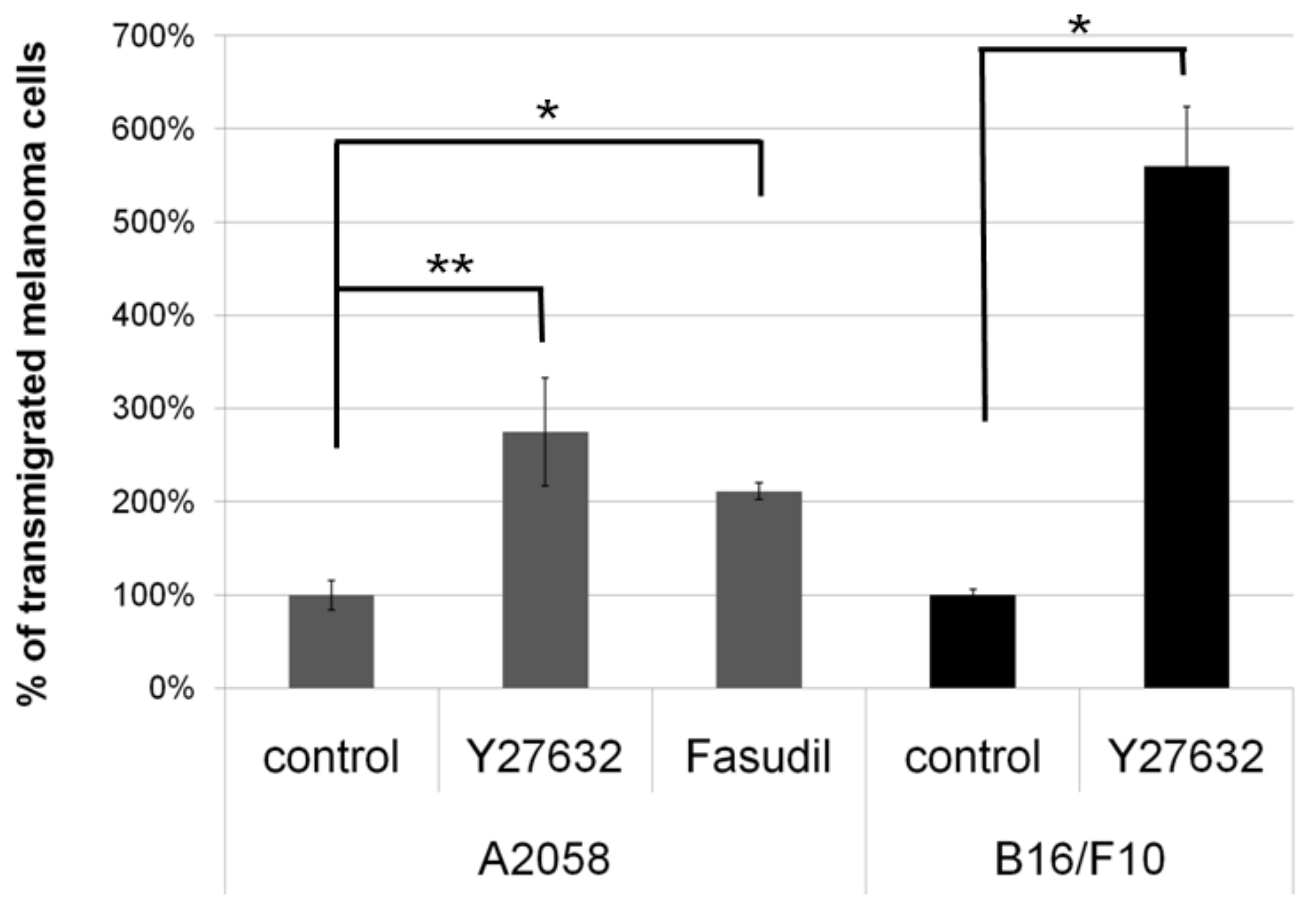

Figure 16: Role of ROCK inhibition in the transendothelial migration of melanoma cells. RBECs were grown until confluency on $8 \mu \mathrm{m}$ pore size filter inserts. Fluorescently labeled melanoma cells (A2058, B16/F10) were plated into the upper chamber in the presence or absence of $10 \mu \mathrm{M}$ Y27632 or $10 \mu \mathrm{M}$ fasudil and left for $5 \mathrm{~h}$. Cells from the upper chamber were removed using a cotton swab, and melanoma cells migrated through the endothelial cell layer and through the pores of the filter were counted. Results are expressed as $\%$ control and given as mean $\pm \mathbf{S D}, * *=\mathbf{P}<0.005 ; *=\mathbf{P}<0.01$ as assessed by Student's t-test, $\mathrm{N}=\mathbf{2 - 5}$.

To address this question melanoma cells were seeded onto endothelial cells cultured on filter inserts. In response to ROCK inhibition the number of melanoma cells performing transendothelial migration increased significantly: by 2.75 or 2.11 fold in case of A2058 melanoma cells treated with Y27632 or fasudil, respectively and by 5.60 fold in case of B16/F10 melanoma cells treated with Y27632 (Figure 16). Migration of melanoma cells in the absence of endothelial cells was not affected by Y27632 as assessed by the wound assay (not shown). 
4.4.5 Melanoma RhoA inhibition is responsible for the increased transmigration rate

To further investigate the role of Rho/ROCK signaling in melanoma cells during transendothelial migration we pretreated either melanoma or endothelial cells with the irreversible Rho inhibitor CT04 and performed transmigration experiments (Figure 17).
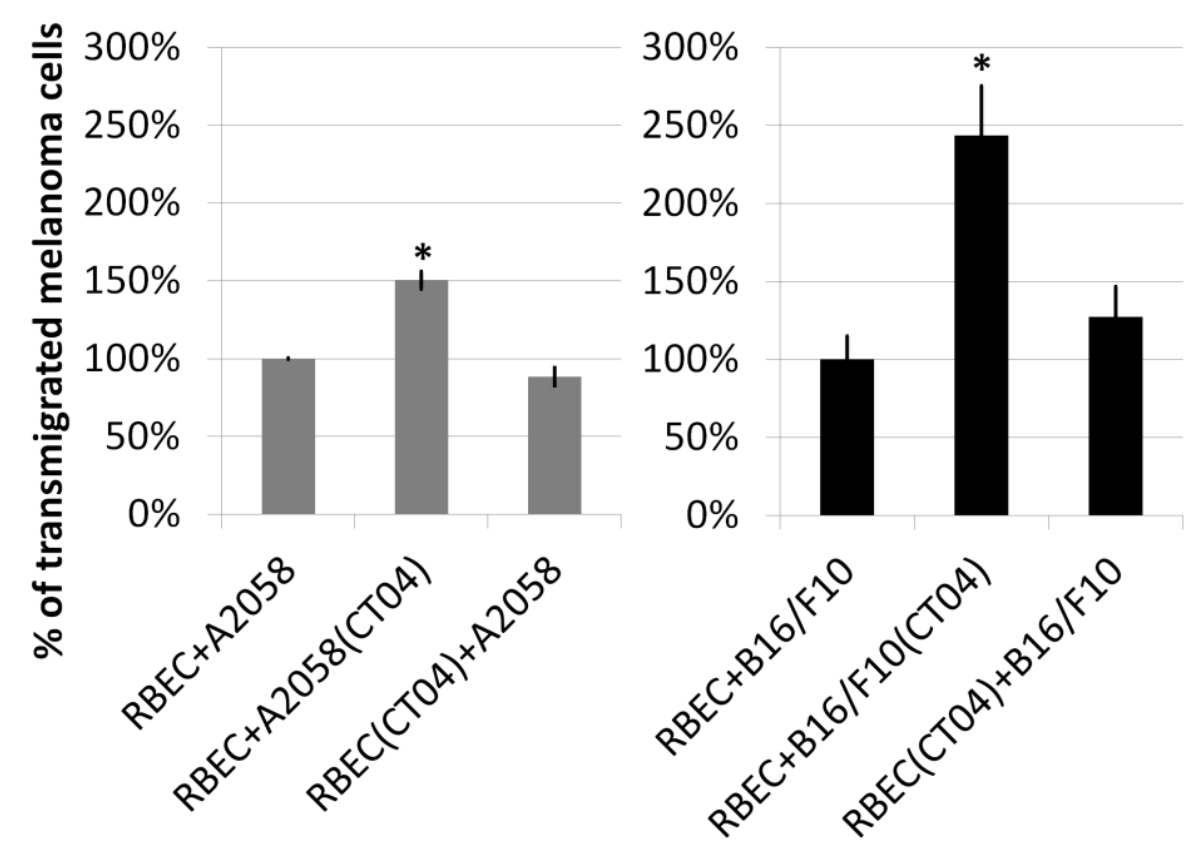

Figure 17: Role of melanoma RhoA in the transendothelial migration. RBEC(CT04), A2058(CT04) and B16/F10(CT04) represent cells pretreated with $1 \mu \mathrm{g} / \mathrm{ml}$ CT04 for $150 \mathrm{~min}$. Transendothelial migration was performed for $5 \mathrm{~h}$. Results are expressed as \% control (no CT04 pretreatment) and given as mean $\pm \mathrm{SD} . \mathbf{N}=\mathbf{2 ,} * \mathbf{*}<\mathbf{0 . 0 5}$ compared to control, as assessed by ANOVA and Bonferroni's post hoc test.

Pretreatment of endothelial cells with CT04 had no effect on the number of melanoma cells migrated through the endothelial monolayer. Conversely, pretreatment of melanoma cells with CT04 induced a significant increase in the number of melanoma cells migrating from the apical to the basolateral side of the endothelium. The increase was 1.51 fold in case of A2058 cells, and 2.43 fold in case of B16/F10 cells. These results support that inhibition of the Rho/ROCK pathway in melanoma, but not in brain endothelial cells induces a significant increase in the number of melanoma cells migrating through the endothelium. 
4.4.6 ROCK inhibitor promotes melanoma brain metastasis formation in vivo

Finally, we have studied the role of ROCK inhibition on melanoma brain metastasis formation in vivo as well. B16/F10 melanoma cells were injected into the carotid artery of C57/BL6 syngeneic mice, some of which were additionally administered $500 \mu \mathrm{g} / \mathrm{kg}$ Y27632 intravenously.

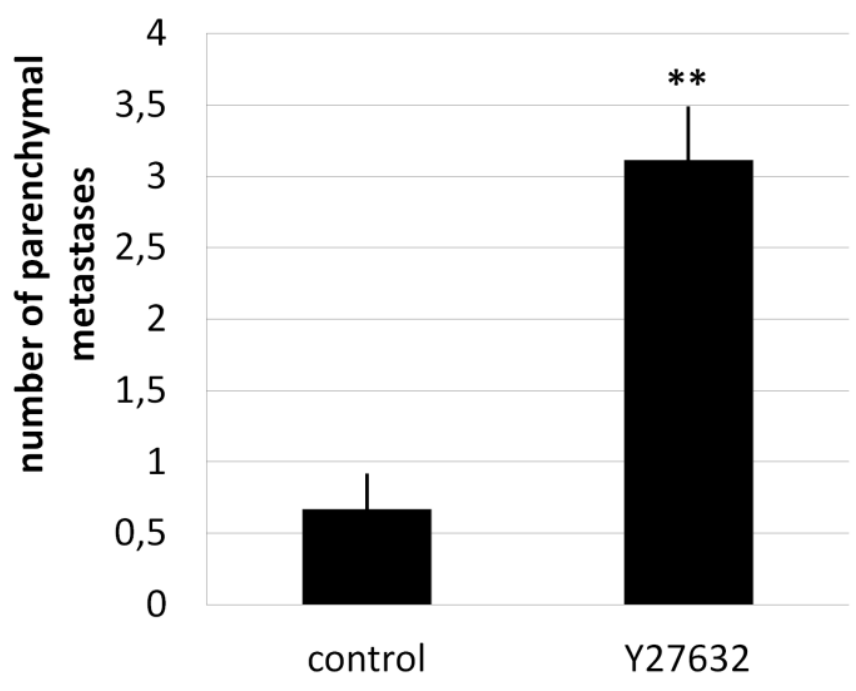

Figure 18: Effect of ROCK inhibition on parenchymal brain metastasis formation in vivo. B16/F10 melanoma cells were injected into C57/BL6 mice. Y27632 was administered intravenously in a dose of $500 \mu \mathrm{g} / \mathrm{kg}$. After 10 days animals were sacrificed and parenchymal metastases were counted in the brains. Graph represents mean $\pm \mathrm{SEM}, \mathrm{N}=6, * *=\mathrm{P}<0.005$ as assessed by Student's t-test.

In control conditions, B16/F10 was able to form mainly non-parenchymal (meningeal and ventricular) metastases, only $0.67 \pm 0.24$ parenchymal metastasis per mouse could be observed. However, in mice treated with Y27632 the number of parenchymal metastases increased significantly to $3.11 \pm 0.37$ per mouse (Figure 18). 


\section{Discussion}

One of the rate limiting steps of melanoma brain metastasis formation is the extravasation through the blood-brain barrier, which requires adhesion of tumor cells to cerebral endothelial cells and subsequently their transmigration through the capillary wall. In order to understand the mechanisms of melanoma brain metastasis formation we applied an in vitro BBB model to study the interaction between melanoma and brain endothelial cells.

\subsection{In vitro BBB model for the study of melanoma-endothelial interaction}

The in vitro BBB model used in our experiments is based on the culture of primary rat brain endothelial cells (RBECs) or the human cerebral endothelial cell line hCMEC/D3 (D3). RBECs in our culture system maintain the main in vivo characteristics of the brain endothelium, such as expression of von Willebrand factor, presence of a continuous line of tight junctions, high transendothelial electrical resistance (TEER) and low permeability values and high activity of P-glycoprotein. However, the fact that rodents develop in very rare instances spontaneous melanoma brain metastases (Cranmer et al. 2005) points towards significant differences between the human and animal disease. This makes necessary the use of human endothelial cells despite their inferior permeability characteristics. Moreover, it has been shown that human melanoma cells injected into mice give spontaneous CNS metastasis (Kienast et al. 2010), therefore a xenogeneic model can also be accepted. The hCMEC/D3 cell line (Weksler et al. 2005) is the most well characterized human brain endothelial cell line, which has been widely used as a human BBB model (Carl et al. 2010, Forster et al. 2008).

We have used the A2058 cell line, which has been shown to produce brain metastasis when injected into immunodeficient mice (Kienast et al. 2010). Additionally we have used murine B16/F10 cells, which initially were adapted to form lung metastasis; however, they are able to form brain metastases as well (Raz, Hart 1980, Bridle et al. 2010). 
Our adhesion experiments revealed that both melanoma cells attached in a higher number to D3 cells than to RBECs. This might be due to the difference in the human and rat adhesion molecules, but also to the lower tightness of the barrier formed by the human cell line.

We have performed time-lapse video experiments, which demonstrated that transmigrated melanoma cells tended to attract other melanoma cells to migrate through the endothelial cell layer at the same site. We could also visualize that transmigrated melanoma cells moved along the basolateral side of the endothelial monolayer. This is in accordance with the observations of Lu et al. (Lu, Bucana \& Schroit 2007) who described that breast cancer cells injected intracardially into mice extravasated into the brain and aligned themselves along the blood vessels, on the basolateral side of endothelial cells, suggesting that the tumor cells migrated along the vasculature. This "pericyte-like" position of transmigrated tumor cells was also observed by Kienast et al. (Kienast et al. 2010) using in vivo multiphoton laser scanning microscopy. They have described that melanoma and lung cancer cells could only proliferate in the brain if they maintained a direct contact to the abluminal side of endothelial cells of cerebral capillaries. These results might raise the possibility of a hiding mechanism of tumor cells behind the defense lines (especially the MDR-MRP systems) of the BBB.

\subsection{Melanoma cells impair the integrity of the BBB and use the paracellular pathway of transmigration}

During transmigration, melanoma cells damaged the integrity of the endothelial monolayer, which was supported by the decrease of TEER and the presence of apoptotic endothelial cells. These observations are in accordance with previous results showing that - in contrast to leukocytes - tumor cells do not leave the endothelium intact after diapedesis (Strell, Entschladen 2008).

Regarding the routes of transmigration, there are two theoretical possibilities, which have been intensively studied in the case of leukocytes: the paracellular (through the interendothelial junctions) and the transcellular pathway (through single endothelial cells). A large number of in vitro and in vivo studies have demonstrated that leukocyte diapedesis can occur either by forming a paracellular gap or via the formation of a 
transcellular pore (Carman 2009, Dejana 2006). The phases and molecular mechanisms involved in the extravasation of leukocytes have also been largely characterized. Since the CNS is an immunologically privileged site, transendothelial migration of leukocytes through the $\mathrm{BBB}$ is practically limited to neuroinflammation. Mononuclear cells can traverse the inflamed BBB both through the tight junctions (paracellular pathway) (Reijerkerk et al. 2006) and transcellularly (Wolburg, Wolburg-Buchholz \& Engelhardt 2005).

We have shown that melanoma cells are able to disrupt interendothelial junctions and to migrate using the paracellular route. However, these results do not exclude the possibility that melanoma cells might take the transcellular pathway as well. The maintenance of low paracellular permeability of the BBB depends on claudin-5 and occludin transmembrane proteins. Interaction between melanoma and endothelial cells resulted in disappearance of claudin-5 and occludin from cell junctions and subsequently in degradation of these junctional proteins in ECs.

\subsection{Role of proteases in the extravasation of melanoma cells}

The breakdown of the endothelial barrier draw our attention to the possible involvement of melanoma-secreted proteases in this process. Tumor cells produce proteases, which are required for the intravasation, extravasation and invasion of the surrounding tissue. Moreover, tight junction proteins might be targets of proteolytic degradation (Reijerkerk et al. 2006) too.

The plasminogen/plasmin system has been shown to facilitate the transmigration of melanoma cells through brain endothelial cells both in vivo and in vitro (Perides et al. 2006). Melanoma cells are able to express several types of proteases including u-PA (Artym et al. 2002), seprase (Monsky et al. 1994, Pineiro-Sanchez et al. 1997) and matrix metalloproteinases (Sounni et al. 2002) which have been shown to promote their invasive potential.

Our results demonstrate that during the transendothelial migration process melanoma cells express large amounts of both secreted and membrane-bound proteases with gelatinolytic activity. Much to our surprise the majority of these enzymes proved to be not matrix metalloproteinases, since addition of EDTA to the incubation buffer did not 
decrease the number and intensity of the proteolytic bands. In contrast, after addition of the irreversible serine protease inhibitor Pefabloc ${ }^{\circledR}$ to the culture medium the gelatinolytic bands almost completely disappeared and the number of melanoma cells migrated through the brain endothelial monolayer decreased significantly.

We have examined whether among these gelatinolytic serine proteases seprase and/or its degradation products were present. Seprase (surface expressed protease) or FAP $\alpha$ (fibroblast activation protein $\alpha$ ) is a type II transmembrane glycoprotein, originally identified in LOX melanoma cells (Pineiro-Sanchez et al. 1997), contributing to the invasiveness of melanoma and carcinoma cells (O'Brien, O'Connor 2008). It has two types of EDTA-resistant protease activities: dipeptidyl peptidase and a $170 \mathrm{kDa}$ gelatinase activity. Dimerization and glycosylation of seprase are necessary for its proteolytic activity. Seprase has been identified as a potential marker protease of invasiveness, localized on invadopodia of malignant melanoma cells (Monsky et al. 1994). Seprase shares homology with dipeptidyl peptidase IV (DPPIV). The latter is expressed by normal melanocytes, epithelial and other cells, while seprase is characteristic for tumor and proliferating mesenchymal cells (Gilmore et al. 2006, Wesley et al. 1999). Using PCR we have found that human brain endothelial D3 cells express DPPIV, but do not express seprase, while A2058 human melanoma cells express seprase, but not DPPIV (not shown). By gelatin zymography coupled with gene silencing we have shown that A2058, but not B16/F10 cells express seprase in the Triton X-114-extractable membrane fraction. However, several other gelatinolytic serine proteases were expressed by both melanoma cell lines, which did not disappear after seprase-silencing. The identity of these enzymes still needs to be elucidated. Accordingly, silencing of seprase reduced to a lesser extent the number of transendothelially migrated melanoma cells compared to Pefabloc ${ }^{\circledR}$. A recent study has also demonstrated that serine protease inhibition reduced melanoma transendothelial migration through non-cerebral human microvascular endothelial cells (Voura et al. 2013). 


\subsection{Role of the ROCK inhibition-induced mesenchymal phenotype in the interaction of melanoma cells with the brain endothelium}

In tumor cell migration the elevated proteolytic activity is associated with the mesenchymal phenotype. Migration in mesenchymal mode means that tumor cells acquire an elongated morphology, involves firm adhesion and are independent of Rho/ROCK regulation (Sahai, Marshall 2003). Owing to the fact that melanoma proteolytic activity yielded a higher rate of transmigration through the endothelium, we investigated the contribution of Rho/ROCK inhibition in the process.

We observed that upon Rho/ROCK inhibition melanoma cells acquired an elongated shape, with large cellular protrusions. As expected, melanoma cells coming in contact with brain endothelial cells produced gelatinolytic proteases, the amount of which increased in the presence of the ROCK inhibitor Y27632. Previously, an elevated seprase (FAP) expression was observed in the case of invasive glioblastoma cells accompanied by a mesenchymal phenotype (Mikheeva et al. 2010). Based on our experiments, ROCK inhibition raised significantly the number of adherent melanoma cells to endothelium. The Rac1 Rho GTPase is responsible for mesenchymal phenotype (Sanz-Moreno et al. 2008). Indeed when Rac1 was hindered, melanoma cells adhered in a lower number to endothelial cells (data not shown). The involvement of Rac1 signaling and proteolytic activity in melanoma metastasis formation has recently been underlined (Shaverdashvili et al. 2013).

Therefore, it is conceivable that the mesenchymal type of cell movement might be superior to the amoeboid type during migration of melanoma cells through the brain endothelium.

Using single-cell force spectroscopy, we have measured the melanoma-endothelial adhesion force in the absence and presence of Y27632. This method monitors initial steps of cell-cell interaction, before firm adhesion is established. As described previously (Vegh et al. 2012), the total adhesion force is composed of elementary forces of roughly $20 \mathrm{pN}$ size. Present as stair-like jumps on the retraction (retrace) phase of the force curve, they correspond to individual rupture events between the two cells. The total adhesion force can be characterized with the size and the number of elementary jumps. It seems 
that mainly the elevation of the number of the ruptures is responsible for the ROCK inhibitor-induced increase in the total adhesion force; the average size of the ruptures has grown only transiently. Accordingly, the adhesion force can also be calculated as the number of ruptures (Reeves et al. 2013).

Theoretically the increased adhesiveness can be due to the increased expression of adhesion molecules in endothelial and/or melanoma cells, to the increased affinity and/or velocity of the adhesion molecule(s), or to the increase in the number of adhesion molecules coming in contact with their target (i.e. increase in the contact surface between the two cell types). Cell flattening might result in an increase in the intercellular contact area, making more surface molecules accessible. Therefore, the ROCK inhibitor-induced morphological changes themselves might be partly responsible for the increase in the adhesion force between melanoma and endothelial cells.

Our data revealed that increased adhesion of melanoma cells was accompanied by an elevated rate of transmigration and a significant increase in the number of brain metastases in vivo. Using B16/F10 murine melanoma cells we could observe a relatively low number of parenchymal brain metastases, which is consistent with literature data (Zhang et al. 2009). Leptomeningeal and ventricular metastases were more frequent. However - since we wanted to evaluate metastatic cells migrated through the BBB these were not counted; only metastases of at least $500 \mu \mathrm{m}$ distances from the meninges and ventricles were considered. In mice treated with Y27632, the number of parenchymal metastases was still low, but significantly higher than in control conditions, which confirms our in vitro results.

According to our results, migration of melanoma cells through the BBB seems to depend on tumor but not on endothelial Rho/ROCK signaling and ROCK-I and ROCK-II have redundant functions. Brain endothelial tight junction proteins, which were shown to be involved in the transmigration of melanoma cells, are linked to the actin cytoskeleton and are influenced by ROCKs. Inhibition of Rho/ROCK signaling has been shown to prevent $\mathrm{Ca}^{2+}$-induced junctional disassembly in both epithelial and brain endothelial cells (Samarin et al. 2007, Wilhelm et al. 2007). ROCK enhances BBB permeability via disruption of tight junction proteins in subarachnoid hemorrhage (Fujii et al. 2012), while inhibition of ROCK was found to attenuate the HIV-1 Tat protein-induced decrease in occludin levels in brain endothelial cells (Xu et al. 2012). 
These data indicate that inhibition of the Rho/ROCK pathway prevents the disruption of the tight junctions in different pathological conditions. Moreover, the ROCK inhibitor Y27632 increased the transendothelial electrical resistance of cerebral endothelial cells (unpublished results). Therefore, it is not surprising that the increase in transendothelial migration rate of melanoma cells was not due to the inhibition of endothelial Rho/ROCK pathway. However, Li et al. (Li et al. 2006) have observed that inhibition of endothelial ROCK with Y27632 or overexpression of a ROCK dominantnegative mutant in endothelial cells prevented NCI-H209 small cell lung cancer cells to migrate through a brain endothelial monolayer. These data suggest that different tumor cell types may activate different mechanisms during transendothelial migration. 
In conclusion, our in vitro results suggest that during brain metastasis formation melanoma cells damage the integrity of the BBB by inducing apoptosis of endothelial cells and by disrupting the continuity of the tight junctions. Transmigrating melanoma cells are able to use the paracellular pathway to overcome the cerebral endothelial monolayer and seem to be able to hide behind the defense lines of the BBB.

During their transendothelial migration, melanoma cells produce serine proteases capable of degrading the components of the basement membrane of capillaries. Inhibition of these proteases can significantly reduce the number of extravasating melanoma cells.

Our data demonstrate that inhibition of the Rho/ROCK pathway in melanoma cells enhances transmigration of melanoma cells through the BBB. We have identified the increased attachment of melanoma cells to the brain endothelium as an underlying mechanism. It may be hypothesized that this might depend on the flattening of melanoma cells.

Our data suggest that the mesenchymal type of cell movement (characterized by: low ROCK activity, increased proteolysis and elongated morphology) is more important than the amoeboid type during migration of melanoma cells through the brain endothelium. 


\section{Summary}

Brain metastases represent the majority of intracranial tumors and are associated with high morbidity. Because CNS lacks lymphatic circulation, during brain metastasis formation tumor cells have to migrate through cerebral endothelial cells, which form the morphological basis of the blood-brain barrier (BBB). Melanoma has the highest propensity to metastasize to the brain; however, the mechanisms of interaction of melanoma cells with endothelial cells of the blood-brain barrier are incompletely understood.

In order to gain insights into plausible mechanisms involved in this process we have used an in vitro experimental setup based on the culture of cerebral endothelial cells and melanoma cell lines, respectively.

We have demonstrated that during brain metastasis formation, melanoma cells impair the integrity of the BBB by inducing apoptosis of endothelial cells and by generating discontinuity of the tight junctions. Melanoma cells migrate paracellularly to penetrate beneath the endothelial monolayer.

We have shown that transendothelial migration of melanoma cells is enhanced by expressed and secreted serine proteases, including seprase. Inhibition of these proteases decreases the rate of transendothelial migration.

In addition, we have investigated the possible involvement of the Rho/ROCK signaling pathway in melanoma BBB crossing.

Our experiments revealed that inhibition of the Rho/ROCK pathway in melanoma cells enhances transmigration through the BBB. We have identified the increased attachment of melanoma cells to the brain endothelium as an underlying mechanism.

Our data indicate that the mesenchymal type of cell movement (characterized by: low ROCK activity, increased proteolysis and elongated morphology) is more important than the amoeboid type during migration of melanoma cells through the brain endothelium. 


\section{References}

Abbott, N.J., Patabendige, A.A., Dolman, D.E., Yusof, S.R., and Begley, D.J. (2010). Structure and function of the blood-brain barrier. Neurobiol. Dis. 37, 13-25.

Abbott, N.J., Ronnback, L., and Hansson, E. (2006). Astrocyte-endothelial interactions at the blood-brain barrier. Nat. Rev. Neurosci. 7, 41-53.

Ahn, J., Sanz-Moreno, V., and Marshall, C.J. (2012). The metastasis gene NEDD9 product acts through integrin beta3 and Src to promote mesenchymal motility and inhibit amoeboid motility. J. Cell. Sci. 125, 1814-1826.

Anfuso, C.D., Giurdanella, G., Motta, C., Muriana, S., Lupo, G., Ragusa, N., and Alberghina, M. (2009). PKCalpha-MAPK/ERK-phospholipase A2 signaling is required for human melanoma-enhanced brain endothelial cell proliferation and motility. Microvasc. Res. 78, 338-357.

Armulik, A., Genove, G., Mae, M. et al. (2010). Pericytes regulate the blood-brain barrier. Nature 468, 557-561.

Artym, V.V., Kindzelskii, A.L., Chen, W.T., and Petty, H.R. (2002). Molecular proximity of seprase and the urokinase-type plasminogen activator receptor on malignant melanoma cell membranes: dependence on betal integrins and the cytoskeleton. Carcinogenesis 23, 1593-1601.

Barnholtz-Sloan, J.S., Sloan, A.E., Davis, F.G., Vigneau, F.D., Lai, P., and Sawaya, R.E. (2004). Incidence proportions of brain metastases in patients diagnosed (1973 to 2001) in the Metropolitan Detroit Cancer Surveillance System. J. Clin. Oncol. 22, 2865-2872.

Bauer, H.C., Traweger, A., Zweimueller-Mayer, J., Lehner, C., Tempfer, H., Krizbai, I., Wilhelm, I., and Bauer, H. (2011). New aspects of the molecular constituents of tissue barriers. J. Neural Transm. 118, 7-21.

Bridle, B.W., Li, J., Jiang, S., Chang, R., Lichty, B.D., Bramson, J.L., and Wan, Y. (2010). Immunotherapy can reject intracranial tumor cells without damaging the brain despite sharing the target antigen. J. Immunol. 184, 4269-4275.

Carbonell, W.S., Ansorge, O., Sibson, N., and Muschel, R. (2009). The vascular basement membrane as "soil" in brain metastasis. PLoS One 4, e5857.

Carl, S.M., Lindley, D.J., Couraud, P.O., Weksler, B.B., Romero, I., Mowery, S.A., and Knipp, G.T. (2010). ABC and SLC transporter expression and pot substrate characterization across the human CMEC/D3 blood-brain barrier cell line. Mol. Pharm. 7, 1057-1068. 
Carman, C.V. (2009). Mechanisms for transcellular diapedesis: probing and pathfinding by 'invadosome-like protrusions'. J. Cell. Sci. 122, 3025-3035.

Citi, S., Sabanay, H., Kendrick-Jones, J., and Geiger, B. (1989). Cingulin: characterization and localization. J. Cell. Sci. 93 ( Pt 1), 107-122.

Colone, M., Calcabrini, A., Toccacieli, L. et al. (2008). The multidrug transporter Pglycoprotein: a mediator of melanoma invasion?. J. Invest. Dermatol. 128, 957-971.

Cranmer, L.D., Trevor, K.T., Bandlamuri, S., and Hersh, E.M. (2005). Rodent models of brain metastasis in melanoma. Melanoma Res. 15, 325-356.

Davis, F.G., Dolecek, T.A., McCarthy, B.J., and Villano, J.L. (2012). Toward determining the lifetime occurrence of metastatic brain tumors estimated from 2007 United States cancer incidence data. Neuro Oncol. 14, 1171-1177.

Dejana, E. (2006). The transcellular railway: insights into leukocyte diapedesis. Nat. Cell Biol. 8, 105-107.

Denkins, Y., Reiland, J., Roy, M., Sinnappah-Kang, N.D., Galjour, J., Murry, B.P., Blust, J., Aucoin, R., and Marchetti, D. (2004). Brain metastases in melanoma: roles of neurotrophins. Neuro Oncol. 6, 154-165.

Dore-Duffy, P. (2008). Pericytes: pluripotent cells of the blood brain barrier. Curr. Pharm. Des. 14, 1581-1593.

Feng, S., Cen, J., Huang, Y., Shen, H., Yao, L., Wang, Y., and Chen, Z. (2011). Matrix metalloproteinase-2 and -9 secreted by leukemic cells increase the permeability of blood-brain barrier by disrupting tight junction proteins. PLoS One 6, e20599.

Fidler, I.J. (2011). The role of the organ microenvironment in brain metastasis. Semin. Cancer Biol. 21, 107-112.

Fidler, I.J., Schackert, G., Zhang, R.D., Radinsky, R., and Fujimaki, T. (1999). The biology of melanoma brain metastasis. Cancer Metastasis Rev. 18, 387-400.

Fokas, E., Steinbach, J.P., and Rodel, C. (2013). Biology of brain metastases and novel targeted therapies: time to translate the research. Biochim. Biophys. Acta 1835, 6175 .

Forster, C., Burek, M., Romero, I.A., Weksler, B., Couraud, P.O., and Drenckhahn, D. (2008). Differential effects of hydrocortisone and TNFalpha on tight junction proteins in an in vitro model of the human blood-brain barrier. J. Physiol. 586, 19371949. 
Fujii, M., Duris, K., Altay, O., Soejima, Y., Sherchan, P., and Zhang, J.H. (2012). Inhibition of Rho kinase by hydroxyfasudil attenuates brain edema after subarachnoid hemorrhage in rats. Neurochem. Int. 60, 327-333.

Fujita, M., Otsuka, Y., Yamada, S., Iwakawa, M., and Imai, T. (2011). X-ray irradiation and Rho-kinase inhibitor additively induce invasiveness of the cells of the pancreatic cancer line, MIAPaCa-2, which exhibits mesenchymal and amoeboid motility. Cancer. Sci. 102, 792-798.

Fukuhara, A., Irie, K., Nakanishi, H. et al. (2002). Involvement of nectin in the localization of junctional adhesion molecule at tight junctions. Oncogene 21, 76427655 .

Furuse, M., Hirase, T., Itoh, M., Nagafuchi, A., Yonemura, S., Tsukita, S., and Tsukita, S. (1993). Occludin: a novel integral membrane protein localizing at tight junctions. J. Cell Biol. 123, 1777-1788.

Ghislin, S., Obino, D., Middendorp, S., Boggetto, N., Alcaide-Loridan, C., and Deshayes, F. (2012). LFA-1 and ICAM-1 expression induced during melanoma-endothelial cell co-culture favors the transendothelial migration of melanoma cell lines in vitro. BMC Cancer 12, 455-2407-12-455.

Ghislin, S., Obino, D., Middendorp, S., Boggetto, N., Alcaide-Loridan, C., and Deshayes, F. (2011). Junctional adhesion molecules are required for melanoma cell lines transendothelial migration in vitro. Pigment Cell. Melanoma Res. 24, 504-511.

Gilmore, B.F., Lynas, J.F., Scott, C.J., McGoohan, C., Martin, L., and Walker, B. (2006). Dipeptide proline diphenyl phosphonates are potent, irreversible inhibitors of seprase (FAPalpha). Biochem. Biophys. Res. Commun. 346, 436-446.

Gonzalez-Mariscal, L., Betanzos, A., Nava, P., and Jaramillo, B.E. (2003). Tight junction proteins. Prog. Biophys. Mol. Biol. 81, 1-44.

Gonzalez-Mariscal, L., Tapia, R., and Chamorro, D. (2008). Crosstalk of tight junction components with signaling pathways. Biochim. Biophys. Acta 1778, 729-756.

Gumbiner, B., Lowenkopf, T., and Apatira, D. (1991). Identification of a 160-kDa polypeptide that binds to the tight junction protein ZO-1. Proc. Natl. Acad. Sci. U. S. A. $88,3460-3464$.

Hawkins, B.T., and Davis, T.P. (2005). The blood-brain barrier/neurovascular unit in health and disease. Pharmacol. Rev. 57, 173-185.

Hocker, T.L., Singh, M.K., and Tsao, H. (2008). Melanoma genetics and therapeutic approaches in the 21 st century: moving from the benchside to the bedside. J. Invest. Dermatol. 128, 2575-2595. 
Hutter, J., and Bechhoefer, J. (1993). Calibration of atomic-force microscope tips. Rev. Sci. Instrum. 64, 1868-1873.

Igarashi, Y., Utsumi, H., Chiba, H. et al. (1999). Glial cell line-derived neurotrophic factor induces barrier function of endothelial cells forming the blood-brain barrier. Biochem. Biophys. Res. Commun. 261, 108-112.

Itoh, K., Yoshioka, K., Akedo, H., Uehata, M., Ishizaki, T., and Narumiya, S. (1999). An essential part for Rho-associated kinase in the transcellular invasion of tumor cells. Nat. Med. 5, 221-225.

Kacem, K., Lacombe, P., Seylaz, J., and Bonvento, G. (1998). Structural organization of the perivascular astrocyte endfeet and their relationship with the endothelial glucose transporter: a confocal microscopy study. Glia 23, 1-10.

Kidera, Y., Tsubaki, M., Yamazoe, Y. et al. (2010). Reduction of lung metastasis, cell invasion, and adhesion in mouse melanoma by statin-induced blockade of the Rho/Rho-associated coiled-coil-containing protein kinase pathway. J. Exp. Clin. Cancer Res. 29, 127-9966-29-127.

Kienast, Y., von Baumgarten, L., Fuhrmann, M., Klinkert, W.E., Goldbrunner, R., Herms, J., and Winkler, F. (2010). Real-time imaging reveals the single steps of brain metastasis formation. Nat. Med. 16, 116-122.

Klemke, M., Weschenfelder, T., Konstandin, M.H., and Samstag, Y. (2007). High affinity interaction of integrin alpha4beta1 (VLA-4) and vascular cell adhesion molecule 1 (VCAM-1) enhances migration of human melanoma cells across activated endothelial cell layers. J. Cell. Physiol. 212, 368-374.

Li, B., Zhao, W.D., Tan, Z.M., Fang, W.G., Zhu, L., and Chen, Y.H. (2006). Involvement of Rho/ROCK signalling in small cell lung cancer migration through human brain microvascular endothelial cells. FEBS Lett. 580, 4252-4260.

Lu, W., Bucana, C.D., and Schroit, A.J. (2007). Pathogenesis and vascular integrity of breast cancer brain metastasis. Int. J. Cancer 120, 1023-1026.

Maraveyas, A., Johnson, M.J., Xiao, Y.P., and Noble, S. (2010). Malignant melanoma as a target malignancy for the study of the anti-metastatic properties of the heparins. Cancer Metastasis Rev. 29, 777-784.

Marchetti, D., Parikh, N., Sudol, M., and Gallick, G.E. (1998). Stimulation of the protein tyrosine kinase c-Yes but not c-Src by neurotrophins in human brain-metastatic melanoma cells. Oncogene 16, 3253-3260.

Martin-Padura, I., Lostaglio, S., Schneemann, M. et al. (1998). Junctional adhesion molecule, a novel member of the immunoglobulin superfamily that distributes at 
intercellular junctions and modulates monocyte transmigration. J. Cell Biol. 142, 117-127.

Matsuoka, T., Yashiro, M., Kato, Y., Shinto, O., Kashiwagi, S., and Hirakawa, K. (2011). RhoA/ROCK signaling mediates plasticity of scirrhous gastric carcinoma motility. Clin. Exp. Metastasis 28, 627-636.

Meier, F., Satyamoorthy, K., Nesbit, M., Hsu, M.Y., Schittek, B., Garbe, C., and Herlyn, M. (1998). Molecular events in melanoma development and progression. Front. Biosci. 3, D1005-10.

Mendes, O., Kim, H.T., and Stoica, G. (2005). Expression of MMP2, MMP9 and MMP3 in breast cancer brain metastasis in a rat model. Clin. Exp. Metastasis 22, 237-246.

Mikheeva, S.A., Mikheev, A.M., Petit, A. et al. (2010). TWIST1 promotes invasion through mesenchymal change in human glioblastoma. Mol. Cancer. 9, 194-4598-9194.

Monsky, W.L., Lin, C.Y., Aoyama, A., Kelly, T., Akiyama, S.K., Mueller, S.C., and Chen, W.T. (1994). A potential marker protease of invasiveness, seprase, is localized on invadopodia of human malignant melanoma cells. Cancer Res. 54, 5702-5710.

O'Brien, P., and O'Connor, B.F. (2008). Seprase: an overview of an important matrix serine protease. Biochim. Biophys. Acta 1784, 1130-1145.

Ohnishi, H., Nakahara, T., Furuse, K., Sasaki, H., Tsukita, S., and Furuse, M. (2004). JACOP, a novel plaque protein localizing at the apical junctional complex with sequence similarity to cingulin. J. Biol. Chem. 279, 46014-46022.

Ohtsuki, S., Yamaguchi, H., Katsukura, Y., Asashima, T., and Terasaki, T. (2008). mRNA expression levels of tight junction protein genes in mouse brain capillary endothelial cells highly purified by magnetic cell sorting. J. Neurochem. 104, 147154 .

Peng, H.H., Hodgson, L., Henderson, A.J., and Dong, C. (2005). Involvement of phospholipase $\mathrm{C}$ signaling in melanoma cell-induced endothelial junction disassembly. Front. Biosci. 10, 1597-1606.

Perides, G., Zhuge, Y., Lin, T., Stins, M.F., Bronson, R.T., and Wu, J.K. (2006). The fibrinolytic system facilitates tumor cell migration across the blood-brain barrier in experimental melanoma brain metastasis. BMC Cancer 6, 56.

Pineiro-Sanchez, M.L., Goldstein, L.A., Dodt, J., Howard, L., Yeh, Y., Tran, H., Argraves, W.S., and Chen, W.T. (1997). Identification of the 170-kDa melanoma membrane-bound gelatinase (seprase) as a serine integral membrane protease. J. Biol. Chem. 272, 7595-7601. 
Platta, C.S., Khuntia, D., Mehta, M.P., and Suh, J.H. (2010). Current treatment strategies for brain metastasis and complications from therapeutic techniques: a review of current literature. Am. J. Clin. Oncol. 33, 398-407.

Qi, J., Chen, N., Wang, J., and Siu, C.H. (2005). Transendothelial migration of melanoma cells involves $\mathrm{N}$-cadherin-mediated adhesion and activation of the beta-catenin signaling pathway. Mol. Biol. Cell 16, 4386-4397.

Qi, J., Wang, J., Romanyuk, O., and Siu, C.H. (2006). Involvement of Src family kinases in N-cadherin phosphorylation and beta-catenin dissociation during transendothelial migration of melanoma cells. Mol. Biol. Cell 17, 1261-1272.

Raz, A., and Hart, I.R. (1980). Murine melanoma: a model for intracranial metastasis. Br. J. Cancer 42, 331-341.

Reeves, K.J., Hou, J., Higham, S.E., Sun, Z., Trzeciakowski, J.P., Meininger, G.A., and Brown, N.J. (2013). Selective measurement and manipulation of adhesion forces between cancer cells and bone marrow endothelial cells using atomic force microscopy. Nanomedicine (Lond) 8, 921-934.

Reijerkerk, A., Kooij, G., van der Pol, S.M., Khazen, S., Dijkstra, C.D., and de Vries, H.E. (2006). Diapedesis of monocytes is associated with MMP-mediated occludin disappearance in brain endothelial cells. FASEB J. 20, 2550-2552.

Rolland, Y., Demeule, M., Fenart, L., and Beliveau, R. (2009). Inhibition of melanoma brain metastasis by targeting melanotransferrin at the cell surface. Pigment Cell. Melanoma Res. 22, 86-98.

Routhier, A., Astuccio, M., Lahey, D. et al. (2010). Pharmacological inhibition of Rhokinase signaling with Y-27632 blocks melanoma tumor growth. Oncol. Rep. 23, 861867.

Sahai, E., and Marshall, C.J. (2003). Differing modes of tumour cell invasion have distinct requirements for Rho/ROCK signalling and extracellular proteolysis. Nat. Cell Biol. 5, 711-719.

Samarin, S.N., Ivanov, A.I., Flatau, G., Parkos, C.A., and Nusrat, A. (2007). Rho/Rhoassociated kinase-II signaling mediates disassembly of epithelial apical junctions. Mol. Biol. Cell 18, 3429-3439.

Sanz-Moreno, V., Gadea, G., Ahn, J., Paterson, H., Marra, P., Pinner, S., Sahai, E., and Marshall, C.J. (2008). Rac activation and inactivation control plasticity of tumor cell movement. Cell 135, 510-523. 
Shaverdashvili, K., Wong, P., Ma, J., Zhang, K., Osman, I., and Bedogni, B. (2013). MT1-MMP modulates melanoma cell dissemination and metastasis through activation of MMP2 and RAC1. Pigment Cell. Melanoma Res.

Sobue, K., Yamamoto, N., Yoneda, K. et al. (1999). Induction of blood-brain barrier properties in immortalized bovine brain endothelial cells by astrocytic factors. Neurosci. Res. 35, 155-164.

Sounni, N.E., Baramova, E.N., Munaut, C., Maquoi, E., Frankenne, F., Foidart, J.M., and Noel, A. (2002). Expression of membrane type 1 matrix metalloproteinase (MT1MMP) in A2058 melanoma cells is associated with MMP-2 activation and increased tumor growth and vascularization. Int. J. Cancer 98, 23-28.

Spencer, C., Montalvo, J., McLaughlin, S.R., and Bryan, B.A. (2011). Small molecule inhibition of cytoskeletal dynamics in melanoma tumors results in altered transcriptional expression patterns of key genes involved in tumor initiation and progression. Cancer. Genomics Proteomics 8, 77-85.

Stamatovic, S.M., Keep, R.F., and Andjelkovic, A.V. (2008). Brain endothelial cell-cell junctions: how to "open" the blood brain barrier. Curr. Neuropharmacol. 6, 179-192.

Stevenson, B.R., Siliciano, J.D., Mooseker, M.S., and Goodenough, D.A. (1986). Identification of ZO-1: a high molecular weight polypeptide associated with the tight junction (zonula occludens) in a variety of epithelia. J. Cell Biol. 103, 755-766.

Strell, C., and Entschladen, F. (2008). Extravasation of leukocytes in comparison to tumor cells. Cell. Commun. Signal. 6, 10-811X-6-10.

Takahashi, K., Nakanishi, H., Miyahara, M. et al. (1999). Nectin/PRR: an immunoglobulin-like cell adhesion molecule recruited to cadherin-based adherens junctions through interaction with Afadin, a PDZ domain-containing protein. J. Cell Biol. 145, 539-549.

Terry, S., Nie, M., Matter, K., and Balda, M.S. (2010). Rho signaling and tight junction functions. Physiology (Bethesda) 25, 16-26.

Tontsch, U., and Bauer, H.C. (1991). Glial cells and neurons induce blood-brain barrier related enzymes in cultured cerebral endothelial cells. Brain Res. 539, 247-253.

Vegh, A.G., Fazakas, C., Nagy, K., Wilhelm, I., Molnar, J., Krizbai, I.A., Szegletes, Z., and Varo, G. (2012). Adhesion and stress relaxation forces between melanoma and cerebral endothelial cells. Eur. Biophys. J. 41, 139-145.

Vishnubhotla, R., Bharadwaj, S., Sun, S., Metlushko, V., and Glover, S.C. (2012). Treatment with Y-27632, a ROCK Inhibitor, Increases the Proinvasive Nature of SW620 Cells on 3D Collagen Type 1 Matrix. Int. J. Cell. Biol. 2012, 259142. 
Voura, E.B., English, J.L., Yu, H.Y., Ho, A.T., Subarsky, P., Hill, R.P., Hojilla, C.V., and Khokha, R. (2013). Proteolysis during tumor cell extravasation in vitro: metalloproteinase involvement across tumor cell types. PLoS One 8, e78413.

Voura, E.B., Ramjeesingh, R.A., Montgomery, A.M., and Siu, C.H. (2001). Involvement of integrin alpha(v)beta(3) and cell adhesion molecule L1 in transendothelial migration of melanoma cells. Mol. Biol. Cell 12, 2699-2710.

Waster, P., Rosdahl, I., Gilmore, B.F., and Seifert, O. (2011). Ultraviolet exposure of melanoma cells induces fibroblast activation protein-alpha in fibroblasts: Implications for melanoma invasion. Int. J. Oncol. 39, 193-202.

Weksler, B.B., Subileau, E.A., Perriere, N. et al. (2005). Blood-brain barrier-specific properties of a human adult brain endothelial cell line. FASEB J. 19, 1872-1874.

Wen, P.Y., Black, P.M., and Loeffler, J.S. (2011). Treatment of Metastatic Cancer. In Cancer: Principles and Practice of Oncology, V.T. DeVita, S. Hellman, and S.A. Rosenberg, eds. (Philadelphia, PA: Lippincott and Wilkins).

Wesley, U.V., Albino, A.P., Tiwari, S., and Houghton, A.N. (1999). A role for dipeptidyl peptidase IV in suppressing the malignant phenotype of melanocytic cells. J. Exp. Med. 190, 311-322.

Whiteman, D.C., Pavan, W.J., and Bastian, B.C. (2011). The melanomas: a synthesis of epidemiological, clinical, histopathological, genetic, and biological aspects, supporting distinct subtypes, causal pathways, and cells of origin. Pigment Cell. Melanoma Res. 24, 879-897.

Wilhelm, I., Farkas, A.E., Nagyoszi, P., Varo, G., Balint, Z., Vegh, G.A., Couraud, P.O., Romero, I.A., Weksler, B., and Krizbai, I.A. (2007). Regulation of cerebral endothelial cell morphology by extracellular calcium. Phys. Med. Biol. 52, 62616274 .

Wolburg, H., Wolburg-Buchholz, K., and Engelhardt, B. (2005). Diapedesis of mononuclear cells across cerebral venules during experimental autoimmune encephalomyelitis leaves tight junctions intact. Acta Neuropathol. 109, 181-190.

Wyckoff, J.B., Pinner, S.E., Gschmeissner, S., Condeelis, J.S., and Sahai, E. (2006). ROCK- and myosin-dependent matrix deformation enables protease-independent tumor-cell invasion in vivo. Curr. Biol. 16, 1515-1523.

Xie, T.X., Huang, F.J., Aldape, K.D., Kang, S.H., Liu, M., Gershenwald, J.E., Xie, K., Sawaya, R., and Huang, S. (2006). Activation of stat3 in human melanoma promotes brain metastasis. Cancer Res. 66, 3188-3196. 
Xu, R., Feng, X., Xie, X., Zhang, J., Wu, D., and Xu, L. (2012). HIV-1 Tat protein increases the permeability of brain endothelial cells by both inhibiting occludin expression and cleaving occludin via matrix metalloproteinase-9. Brain Res. 1436, 13-19.

Yang, X., Di, J., Zhang, Y., Zhang, S., Lu, J., Liu, J., and Shi, W. (2012). The Rho-kinase inhibitor inhibits proliferation and metastasis of small cell lung cancer. Biomed. Pharmacother. 66, 221-227.

Yang, X., Liu, Y., Zong, Z., and Tian, D. (2010). The Rho kinase inhibitor fasudil inhibits the migratory behaviour of 95-D lung carcinoma cells. Biomed. Pharmacother. 64, $58-62$.

Yui, Y., Itoh, K., Yoshioka, K. et al. (2010). Mesenchymal mode of migration participates in pulmonary metastasis of mouse osteosarcoma LM8. Clin. Exp. Metastasis 27, 619630.

Zhang, C., Zhang, F., Tsan, R., and Fidler, I.J. (2009). Transforming growth factor-beta2 is a molecular determinant for site-specific melanoma metastasis in the brain. Cancer Res. 69, 828-835.

Zhang, X., Wojcikiewicz, E.P., and Moy, V.T. (2006). Dynamic adhesion of T lymphocytes to endothelial cells revealed by atomic force microscopy. Exp. Biol. Med. (Maywood) 231, 1306-1312. 


\section{Acknowledgements}

I would like to express my deepest gratitude to my supervisor Dr. István Krizbai for scientific guidance and constant support throughout my $\mathrm{PhD}$ studies. I am very grateful to my colleague Dr. Imola Wilhelm for endlessly answering my questions, and for fruitful discussions and encouragement.

I am thankful to Dr. László Siklós, the head of the Molecular Neurobiology unit and to all my colleagues in the group, especially to Ngo Thi Khue Dung for her excellent assistance. I would like to thank Dr. Pál Ormos, the director of the Institute of Biophysics, and all members of the Institute for the pleasant working atmosphere.

I wish to acknowledge my colleagues, Dr. Péter Nagyőszi, János Haskó, Dr. Attila Farkas, Judit Molnár and Ádám Nyúl-Tóth for excellent teamwork, inspiring scientific and personal discussions.

I am grateful to all co-authors for enthusiastic participation in the preparation of experiments and manuscripts, especially to Dr. György Váró and Gergely A. Végh for atomic force microscopy studies.

I am thankful to my friends, for their friendship and emotional support. I am eternally grateful to my family for their unconditional love and support. Particular appreciation regards my husband, Gergő for his patience and for always being there for me.

Finally, I want to thank to Richter Gedeon Foundation and to Jedlik Ányos Ph.D. Candidate Scholarship (TÁMOP 4.2.4.A/2-11-1-2012-0001) for financial support. 